\title{
Sensitivity of a General Circulation Inverse Model to Sub-Grid Scale Parametrization Coefficients
}

\author{
by \\ Eric C. Won \\ Submitted in partial fulfillment of the \\ requirements for the degree of \\ Master of Science \\ at the \\ MASSACHUSETTS INSTITUTE OF TECHNOLOGY \\ and the \\ WOODS HOLE OCEANOGRAPHIC INSTITUTION
}

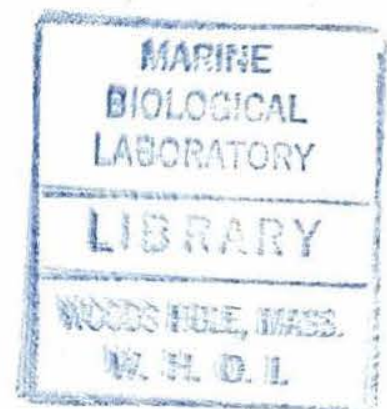

August 1994

(c) Eric C. Won 1994

The author hereby grants to MIT and to WHOI permission to reproduce and to distribute copies of this thesis document in whole or in part.

Signature of Author

Joint Program in Physical Oceanography

Massachusetts Institute of Technology

Woods Hole Oceanographic Institution

August 17, 1994

Certified by .......

2, 1 Thesis Supervisor

Accepted by

Chairman, Joigit Cofnmitee for Physical Oceanography

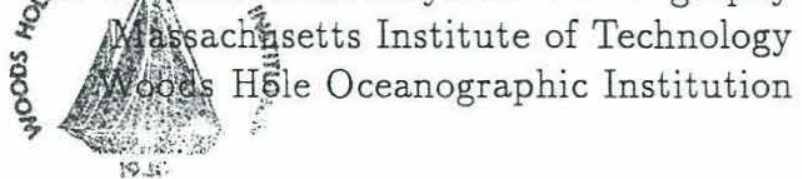




\section{Acknowledgements}

I would like to thank Dir. Lisan Yu for heiping me understand the code and its intricacies, allowing me to use the datasets she prepared for it, and getting me started in UNICOS and NCAR's IRJE; Dr. W. Brechner Owens for helping me to correlate the code's topographic file with a real atlas; Prof. Jochem Marotzke for his helpful comments and criticisms, and particularly for a long conversation one afternoon late April which was particularly illuminating; and especially Prof. Paola Rizzoli who inspired, guided, and supported me along the way. I also thank Bud Brown for his assistance with Figure 3.12. Finally, I thank most of all my wife, Aida, who truly bore me through the entire process. 


\section{Table of Contents}

1 Introduction and Motivation . . . . . . . . . . . . 7

2 The Model ............................. 15

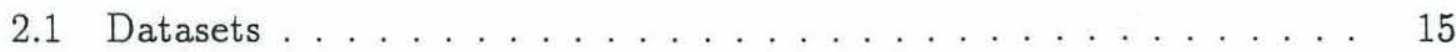

2.2 Forward model . . . . . . . . . . . . . . . 16

2.3 Cost function and adjoint . . . . . . . . . . . . . . 18

3 Numerical Experiments . . . . . . . . . . . . . . . . . . 23

3.1 Residuals ............................ 25

3.2 Basin-wide results . . . . . . . . . . . . . . . 27

3.3 Regional results . . . . . . . . . . . . . . . . . 45

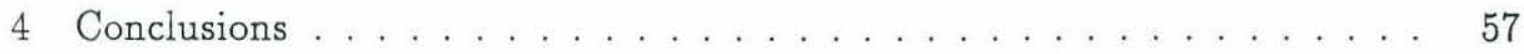

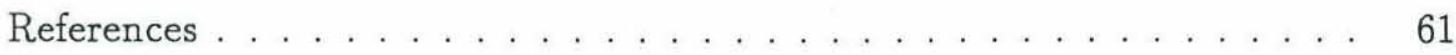




\section{Chapter 1}

\section{Introduction and Motivation}

Ocean modellers seek to understand the circulation of the oceans, or portions thereof, by developing models of the ocean they can solve. This tractability constraint forces

ocean modellers to make choices. Naturally, they hope to make intelligent choices, but whenever a new model is being developed or an existing one extended, the issue of tractability lurks.

The large-scale, basin-wide, circulation of the oceans can be divided into two components, classified by their driving force. The wind-driven circulation, whose flow occurs mainly above the thermocline, was first explained qualitatively by Stommel (1948) with a simple, elegant analytical model. The other component of the oceans' circulation, the density-driven, or thermohaline circulation, flows below the thermocline. Again, the first simple analytical model for the deep thermohaline flow was proposed by Stommel (1958) and developed by Stommel and Aarons (1959) whose basic ideas underlie even the most recent conceptual models of the large-scale circulation. The details of the thermohaline circulation and its interaction with the wind-driven circulation in a realistic ocean basin is a problem which is not tractable analytically. This has driven ocean modellers interested in this aspect of the oceans' circulation to numerical models: ocean circulation models.

There are two kinds of ocean models: diagnostic and prognostic. The diagnostic models, are based on steady-state dynamics of varying complexity. Ranging 
from simple geostrophic calculations to models employing fully nonlinear primitive equation systems, they find the steady-state circulation that is consistent with the available data and the chosen dynamics. The fundamental and insurmountable deficiency of diagnostic models is their steady-state assumption which presupposes a truly steady (not time averaged!) circulation. This assumption, moreover, prevents any dynamical evolution of circulation features, yielding very little information on and insight into processes such as jet instabilities leading to meander steepening and propagation, or ring formation and detachment, observed phenomena in the North Atlantic's Gulf Stream system for example.

Prognostic models bypass the diagnostic models' fundamental deficiency since they compute the time-evolution of the circulation. They do, however, suffer from different deficiencies due to other factors, including approximate dynamics, ill-posed boundary conditions, or poor parametrizations of subgrid-scale processes, for example.

Perhaps the best ("optimal") way to overcome such deficiencies is to combine prognostic models with data assimilation schemes, a type of inverse calculation. This eliminates the basic deficiency of the diagnostic models, the steady-state assumption, and provides an optimal estimate of the circulation that is simultaneously consistent with time-dependent dvnamics and all the available data. Although only recently applied successfully to portions of the ocean with "enough" data, insufficiency of existing global datasets and its immense computational requirements prevent fully time-dependent data assimilation from being applied on a global scale at the moment (Malanotte-Rizzoli 1994).

Prognostic models can be classified by the dynamics they employ. This divides ocean circulation models into into two main categories, quasi-geostrophic (QG) and primitive equation (PE) models. Intermediate categories, such as balanced equation models, have been employed mainly for atmospheric circulation studies and have 
only recently received some attention by the oceanographic community (McWilliams et al. 1990).

QG models, predicated on the smallness of the Rossby number (Pedlosky, 1987), have zero-order velocities in geostrophic balance. The best known examples are the ones developed by Holland (1978). QG models are a good choice for process studies and wind-driven general circulation studies in deep, open ocean regions or in closed or semi-open domains. The QG approximation however fails at first order with any realistic representation of topography, the smallness of the Rossby number disallowing steep slopes which would produce large vertical velocities initially through the kinematic bottom boundary condition. Furthermore, the vertical displacement of each QG isopycnal layer from its level, unperturbed position must also be of order Rossby number, thereby precluding any large vertical isopycnal surface excursions. Finally, although thermodynamic forcing can be introduced into QG models, they cannot really simulate the thermohaline circulation since the order of the thermodynamic forcing, again, cannot exceed the Rossby number, and the QG stratification cannot be changed, obviating the possibility of convection.

PE models mostly bypass the above deficienies and are the most realistic choice, provided one can bear their often large computational expense. Including realistic topography, they can compute the time-evolving circulation resolving vertical stratification, and hence reproduce realistic vertical processes as accuractely as tractability permits. Most importantly, they can be endowed with active thermodynamics, making them suitable for quantitative studies of the thermohaline circulation.

In spite of their advantages, $\mathrm{PE}$ calculations suffer from their own drawbacks and deficiencies, typical examples of which have been experienced by the Community Modelling Effort (CME) of WOCE described by Holland and Bryan (1994a,b). The CME uses the Geophysical Fluid Dynamics Laboratory (GFDL) model of Bryan (1969), with further significant enhancements implemented by Cox (1984). The CME version of the GFDL model focusses on the North Atlantic Ocean circualation with 
a domain from $15^{\circ} \mathrm{S}$ to $65^{\circ} \mathrm{N}$ in latitude. At the northern and southern boundaries, sponge layers are prescribed which relax the temperature and salinity fields to a given climatology, in their case that of Levitus (1982). These artificial boundary conditions are meant to mimic the water masses of the polar seas and the South Atlantic not included in the model domain, and in fact critically affect the development and overall rate of production and volume transport of the North Atlantic Deep Water (NADW) cell. Simulation results are very often at odds with robust observational evidence (Böning et al. 1993).

Holland and Bryan (1994b) review several calculations of the CME, which has 30 vertical levels, at various horizontal resolutions (meridional $\times$ zonal): medium $\left(1.0^{\circ} \times 1.2^{\circ}\right)$, high $\left(1 / 3^{\circ} \times 0.4^{\circ}\right)$, and very-high $\left(1 / 6^{\circ} \times 0.2^{\circ}\right)$. One of their observations is that the zonally averaged northward heat transport is nearly independent of resolution, although the zonally-averaged meridional mass overturning does decrease with increasing resolution. From this they justify further exploration of other factors affecting the thermohaline circualtion with their computationally least expensive medium resolution model. They then describe results of several sensitivity studies with that model, including preliminary results of a study of open boundary conditions. Their preliminary conclusion from that study is that open boundary conditions, at the southern boundary in particular, can significantly increase the northward heat transport, while leaving the meridional overturning essentially unaffected.

Another significant deficiency of $\mathrm{PE}$ calculations resides in the parametrizations of subgrid-scale processes, including both the simulation of vertical convection in the polar seas, which occurs on scales of one kilometer and leads to NADW formation, as well as the parametrization of motions smaller than the model resolution, which is usually done through eddy viscosity coefficients in the horizontal momentum equations and eddy diffusivity coefficients in the tracer equations. Such approximations make prognostic calculations such as the $\mathrm{CME}$ extremely sensitive to the choice of many different parameters, aside from being very sensitive to the choices of "good" 
versus "bad" temperature and salinity climatologies, and surface forcing functions, for example.

Böning et al. (1994), also a part of the CME, focus on a phenomenon which almost all $\mathrm{PE}$ models of the large-scale thermohaline circulation exhibit, including non-CME models: a mid-latitude spurious upwelling in the North Atlantic slopeward of the Gulf Stream which significantly decreases the amount of deep water carried towards low latitudes from the formation regions in the subpolar North Atlantic. Veronis (1975), in a review paper, was the first to focus on this thermohaline shortcut, in an attempt to reconcile the arguments of Stommel (1958) with the numerical computation of Holland (1971). Noticing that the thermocline is a fairly steady global feature of the world's oceans, Stommel (1958) conjectured that the downward diffusion of heat in the oceans' upper layers was balanced by a uniform upwelling from the cold abyssal circulation at the base of the thermocline. At odds with this conjecture, the numerical computation of Holland (1971), based on the original GFDL model of Bryan (1969) which parametrizes subgrid-scale mixing through diffusivities, showed upwelling over roughly half of the basin, and downwelling over the other half. To reconcile this discrepancy, Veronis (1975) performed a scale analysis of the dynamical equations at the Western boundary layer and concluded that the dominant balance there was between the vertical advection and the zonal diffusion, essentially

$$
w \theta_{z} \sim K_{H} \theta_{x x}
$$

where Holland (1971) used $K_{H}=5 \times 10^{7} \mathrm{~cm}^{2} / \mathrm{s}$. Veronis (1975) explained this result physically by arguing that in order to maintain a steady temperature near the insulated boundary, the intense zonal diffusion of heat from the warmer interior had to be balanced by intense upwelling of cooler abyssal waters in that boundary region. This intense localized upwelling had basin-wide consequences in that the abyssal water which upwelled at the boundary was formed not only in the polar seas, but throughout the basin via extended regions of downwelling. Indeed Veronis (1975) concludes his review by citing a privately communicated unpublished result of 
Holland's that a numerical computation with $K_{H}=10^{7} \mathrm{~cm}^{2} / \mathrm{s}$ had weaker upwelling in the boundary laver and upwelling amost everywhere in the interior.

Böning et al. (1994) note that this suspicious upwelling across the Gulf Stream front is observed in almost all CME calculations which use this inadequate diffusivity parametrization of tracer mixing. To avoid this phenomenon, all calculations employing this parametrization would require a very high resolution grid $\left(1 / 6^{\circ}\right.$ at least) to provide adequate resolution of the Gulf Stream front so that diffusive processes become less important. The higher resolution would allow one to choose a smaller horizontal eddy diffusivity $K_{H}$ which should reduce the artificial vertical upwelling that gives rise to the insufficient meridional overturning rates and northward heat transport of these numerical experiments. However, instead of increasing the horizontal resolution, and computational load, Böning et al. (1994) chose to implement a new parametrization of subgrid-scale tracer mixing processes, that of Gent and McWilliams (1990). Their simulation using this parametrization in the tracer equations eliminated the shortcut in the meridional overturning and yielded significant improvements in the above integral measures of the thermohaline circulation including a substantial increase of the northward heat transport to realistic values.

Whatever the reason for the apparent control of the thermohaline circulation and its meridional heat transport by $K_{H}$, Equation (1.0.1) is unlikely to be the entire dominant balance within the boundary region. Integrating the two term balance, which gives

$$
\left.K_{H} \theta_{x}\right|_{\text {boundary }} ^{\text {interior }} \sim \int_{\text {boundary }}^{\text {interior }} w \theta_{z} d x,
$$

we see that since the temperature of the ocean interior is relatively constant and there is no flux of temperature through the boundary,

$$
\int_{\text {boundary }}^{\text {interior }} w \theta_{z} d x \sim 0,
$$


which implies that the intense upwelling shoreward of the Gulf Stream must be balanced by downwelling throughout the interior. This circulation must be completed by zonal flows, which means that the original balance, Equation (1.0.1), is incomplete.

In any case, the study by Böning et al. (1994), which shows not only dramatic sensitivity of prognostic calculations to different parametrizations of horizontal tracer mixing processes, but also demonstrates sensitivity of such calculations to actual values used for the horizontal eddy diffusivity, constitutes a major motivation of the present thesis. For the same medium resolution $\left(1.0^{\circ} \times 1.2^{\circ}\right)$ grid size, Böning et al. reduced $K_{H}$ from $10^{7}$ to $5 \times 10^{6} \mathrm{~cm}^{2} / \mathrm{s}$ and found a significant reduction of upwelling in the region inshore of the Gulf Stream. Here we perform data assimilation calculations with the adjoint model developed for the North Atlantic by Tziperman et al. (1992a,b), studied by Marotzke (1992) and modified by Marotzke and Wunsch (1993) to see if the model exhibits similar sensitivity. The basic principle of these adjoint calculations is to minimize the misfit between the prognostic variables predicted by the PE model and their observational counterparts through a cost function. Providing estimates of the circulation that are optimally consistent with the observations and the dynamics, the adjoint model may rectify, though only partially, some intrinsic inconsistencies of the prognostic model. However, such inverse calculations may themselves be as sensitive as the prognostic ones to the parametrization of mixing processes. Thus in this work two basic questions are addressed:

1. How sensitive are the assimilation calculations to the specification of the eddy diffusivity coefficients, i.e. if we reduce $K_{H}$, do we significantly reduce the vertical upwelling $w$, and also, do different values of $K_{V}$ also affect the circulation?

2. How well (totally or only partially) does the adjoint's optimal fitting to the data correct for the artificial upwelling slopeward of the Gulf Stream observed in the prognostic calculations? 
The remainder of this thesis is organized as follows. Chapter 2, following Marotzke and Wunsch (1993), briefly describes the data sets 1sed, the model, the cost function, and adjoint. Chapter 3 describes the results of the experiments, beginning in Section 1 with a discussion of the residuals of the first experiment, followed in Section 2 with a discussion of results in the basin as a whole and then focussing in Section 3 on the region of spurious upwelling. Finally in Chapter 4 we present the conclusions of this work. 


\section{Chapter 2}

\section{The Model}

The inverse model used, that of Marotzke and Wunsch (1993), consists of a forward $\mathrm{PE}$ model, its variational adjoint, and a cost or penalty function. This discussion follows theirs.

\subsection{Datasets}

The temperature and salinity climatology used was the winter subset of Levitus (1982), which was interpolated via cubic splines in both the horizontal and the vertical onto our (coarse) model grid $\left(2^{\circ} \times 1^{\circ}\right.$, meridional $\times$ zonal) (Yu 1993). Since estimates of uncertainty are not provided with Levitus (1982), we assume that structures of errors should not substantially differ between climatologies and use the uncertainties of Marotzke and Wunsch (1993). We also used the January wind stresses of Hellerman and Rosenstein (1983).

As in Marotzke and Wunsch (1993), we use the surface heat flux climatology of Isemer et al. (1989), which is based on the requirement of a northward heat transport across $25^{\circ} \mathrm{N}$ of 1.2 consistent, petawatts with Hall and Bryden (1982) and others, and the evaporation minus precipitation $(E-P)$ climatology of Schmitt et al. (1989). 


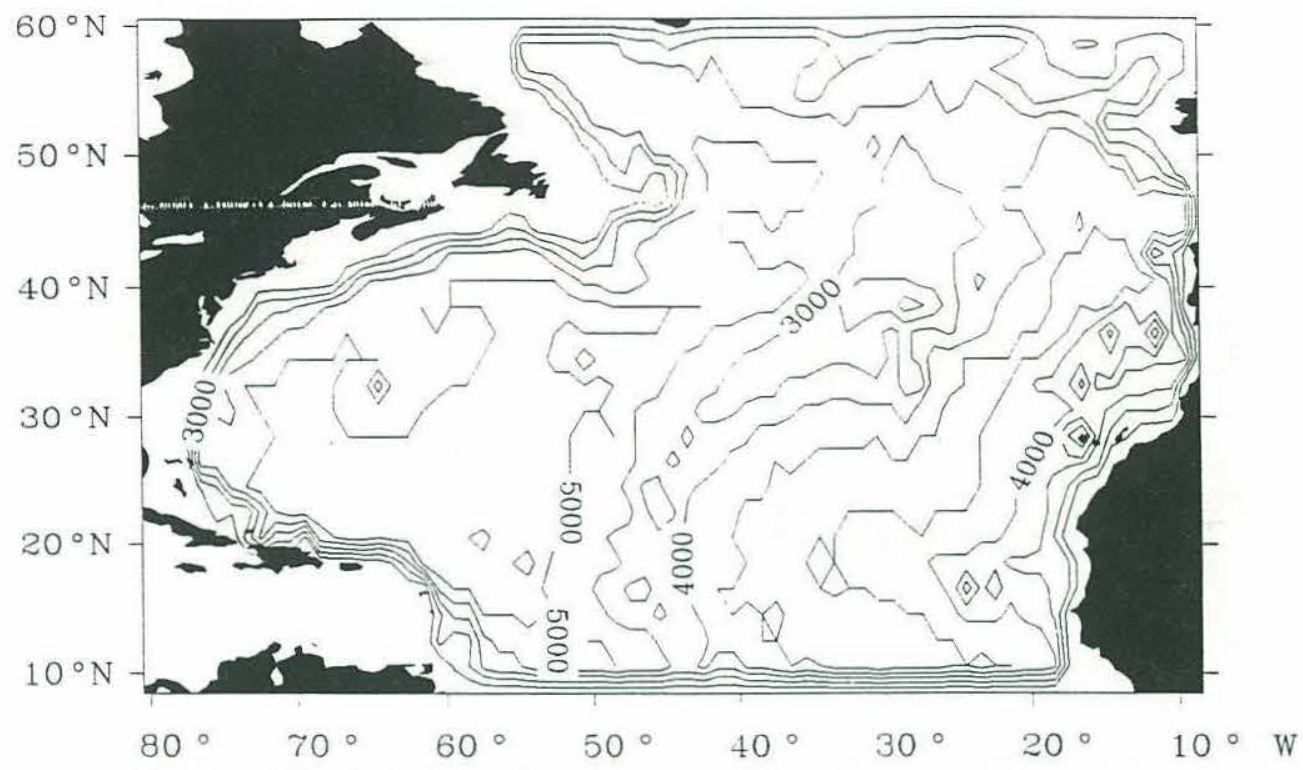

Figure 2.1: Model Domain with Bathymetry. (interval $1000 \mathrm{~m}$ )

\subsection{Forward model}

The model domain is that of the North Atlantic Ocean, extending from $9.5^{\circ}$ to $59.5^{\circ} \mathrm{N}$ and from $80^{\circ}$ to $10^{\circ} \mathrm{W}$. Coarse horizontal resolution, as mentioned above, of $2.0^{\circ}$ meridionally by $1.0^{\circ}$ zonally was chosen in general to reduce the storage and computational burden particularly of the adjoint and anisotropically to allow greater resolution of boundary current structure. Realistic coastlines and bottom topography are used, with up to 24 variably spaced vertical levels having higher resolution above $1000 \mathrm{~m}$ and lower resolution below (Fig. 2.1).

As in the CME, to mimic the effects of heat and salt transports across the northern and southern walls, the temperature and salinity are restored to climatology (Levitus 1982, winter) in sponge layers $2^{\circ}$ thick with a time constant of 1 day. Since no hydrographic data exist for parts of the Carribean Sea and the Gulf of Mexico, the Antilles form the southwest boundaries of the model, and crude open boundary conditions are applied there (Marotzke and Wunsch 1993). The inflow into the North Atlantic basin through the Straits of Florida $\left(27.5^{\circ} \mathrm{N}, 79^{\circ} \mathrm{W}\right)$ is set at $30 \mathrm{~Sv}$ with the temperature inferred from Leaman et al. $(1987,1989)$, and salinity assumed to be 
the horizontal averages of the R/V Atlantis 109 section Florida-Fort Pierce at $27^{\circ} \mathrm{N}$ (Roemmich and Wunsch 1985). The offsetting outflows from the North Atlantic basin into the Caribbean follow the results of Roemmich (1981) with an $8 \mathrm{~Sv}$ flow through the Windward Passage $\left(19.5^{\circ} \mathrm{N}, 73^{\circ} \mathrm{W}\right)$ and a $22 \mathrm{~Sv}$ flow through the eastern passages $\left(13.5^{\circ}, 15.5^{\circ} \mathrm{N} ; 61^{\circ} \mathrm{W}\right)$ and temperature and salinity specified from the observed climatology. All open boundary conditions have a specified depth structure (Marotzke and Wunsch 1993).

The model adjoint code was first developed by Tziperman et al. (1992a, b), based on the PE OGCM of Bryan (1969) with the enhancements of Cox (1984). However in the model's horizontal momentum equations, local time derivatives and advection are neglected, and a Rayleigh friction is used instead of the original horizontal and vertical eddy parametrizations. These modifications were chosen mainly to reduce the computational burden of the forward model, and consequently its adjoint, since essentially diagnostic momentum equations permit larger time steps. These modifications also mean that the dynamics will be governed by the density through the fully active temperature and salinity equations. The governing equations of the forward model, then, are

$$
\begin{aligned}
\mathbf{f} \times \mathbf{u} & =-\frac{1}{\rho_{0}} \nabla p-r \mathbf{u} \\
\frac{\partial \theta}{\partial t}+(\mathbf{u} \cdot \nabla) \theta+w \frac{\partial \theta}{\partial z} & =K_{H} \nabla^{2} \theta+K_{V} \frac{\partial^{2} \theta}{\partial z^{2}}+C_{\theta} \\
\frac{\partial S}{\partial t}+(\mathbf{u} \cdot \nabla) S+w \frac{\partial S}{\partial z} & =K_{H} \nabla^{2} S+K_{V} \frac{\partial^{2} S}{\partial z^{2}}+C_{S} \\
\nabla \cdot \mathbf{u}+\frac{\partial w}{\partial z} & =0 \\
0 & =-\frac{\partial p}{\partial z}-g \rho \\
\rho & =\rho(\theta, S, p) .
\end{aligned}
$$

The equation of state (2.2.1f) is a polynomial approximation. The terms $C_{\theta}$ and $C_{S}$ in the tracer equations $(2.2 .1 \mathrm{~b}-\mathrm{c})$ represent the removal of static instability by a simulated convective adjustment process. Here we augmented the scheme of Marotzke 
and Wunsch (1993) by using four adjustment passes instead of their one (Yu 1993). The timestep used was 12 hours; and $r=5 \times 10^{-7} \mathrm{~s}^{-1}$.

\subsection{Cost function and adjoint}

The key to this approach is the scalar quadratic cost function, whose minimum is sought, and the keys to the cost function are its weights, whose magnitudes relative to each other determine the relative importance of their corresponding quadratic terms. The following quantities and operators appear in the cost function. The state vector, $\mathbf{x}(t)$, in this case the potential temperature and salinity, completely specifies the model at time $t$. The observations, y, are the Levitus (1982) winter potential temperature and salinity, the Isemer et al. (1989) heat flux, and the Schmitt et al. (1989) $(E-P)$ climatologies. The data weight matrix $W_{D}$ is chosen to be the inverse of the error covariance matrix of the data. For uncorrelated data, as is assumed to be the case here, the error covariance matrix is diagonal, and its inverse is simply the reciprocal of the diagonal terms. Therefore, observations with large errors have small weights, and those with small errors have large weights. Note that the surface climatologies, wind-stress and heat and evaporation fluxes, were not included in the cost function since we did not want to over-constrain the optimization and their larger uncertainties would suggest they would make little contribution to the cost function anyway. The steady weight matrix, $W_{S}$, specifies how stringently steadiness is demanded and is chosen after Marotzke and Wunsch (1993) for an adjustment time $\tau=10$ years. Here we perform data assimilation in an ocean basin with the simplest assumption, that of steadiness, and seek time-dependence only if warranted later. Thus, in its current configuration, the entire scheme searches for a steady solution which is simultaneously consistent with the datasets and forward $\mathrm{PE}$ dynamics. The Lagrange multipliers $\mathrm{h}(t)$, which are determined iteratively through the adjoint model, provide an efficient method for computing the gradients of the cost function, which can then be used to find its minimum. The operator $E$ relates the 
state vector at the model grid points to the observations in

$$
\mathbf{y}=\operatorname{Ex}(t)+\mathbf{n}(t)
$$

where $\mathbf{n}(t)$ is the noise in the observations. Finally the forward model itself is symbolized as

$$
\mathcal{G}[\mathbf{x}(t) \text {; (boundary conditions) }]
$$

in

$$
\mathbf{x}(t+1)=\mathcal{G}[\mathbf{x}(t)],
$$

where the time step $\Delta t$ has been normalized to 1 . Following the above notations, the cost function takes the quadratic form

$$
\begin{aligned}
J=\frac{1}{2} \sum_{t=0}^{t_{f}}[\mathbf{y}-E \mathbf{x}(t)]^{\top} W_{D}[\mathbf{y}-E \mathbf{x}(t)] \\
\quad+\frac{1}{2}\left[\mathbf{x}\left(t_{f}\right)-\mathbf{x}(0)\right]^{\top} W_{\mathbf{S}}\left[\mathbf{x}\left(t_{f}\right)-\mathbf{x}(0)\right] .
\end{aligned}
$$

The first term contains the data misfit terms: $\theta$ misfit, $S$ misfit and surface flux misfits. The second term is the steadiness portion of the cost function. The Lagrange function, $L$, is obtained by appending Lagrange multipliers, $\mathbf{h}(\mathrm{t})$, times the forward model to the cost function,

$$
L=J-\sum_{t=0}^{t} \mathbf{f}-1
$$

Note that since the model is satisfied exactly, the numerical value of $L=J$, and in particular, their extrma are identical.

The minima of $L$, and also $J$, are attained when its first partials vanish.

$$
\begin{aligned}
& 0=\frac{\partial L}{\partial \mathbf{h}(t+1)}=\mathbf{x}(t+1)-\mathcal{G}[\mathbf{x}(t)], \quad 0 \leq t \leq t_{f}-1 \\
& 0=\frac{\partial L}{\partial \mathbf{x}\left(t_{f}\right)}=E^{\top} W_{D}\left[\operatorname{Ex}\left(t_{f}\right)-\mathbf{y}\right]+W_{S}\left[\mathbf{x}\left(t_{f}\right)-\mathbf{x}(0)\right]-\mathbf{h}\left(t_{f}\right) \\
& 0=\frac{\partial L}{\partial \mathbf{x}(t)}=E^{\top} W_{D}[\operatorname{Ex}(t)-\mathbf{y}]+\frac{\partial \mathcal{G}}{\partial \mathbf{x}(t)}^{\top} \mathrm{h}(t+1)-\mathbf{h}(t),
\end{aligned}
$$




$$
\begin{aligned}
& 1 \leq t \leq t_{f}-1 \\
& 0=\frac{\partial L}{\partial \mathbf{x}(0)}=F^{\top} W_{D}[\mathrm{Fx}(0)-y] \\
& -\mathrm{W}_{\mathbf{S}}\left[\mathbf{x}\left(t_{f}\right)-\mathbf{x}(0)\right]+\frac{\partial \mathcal{G}}{\partial \mathbf{x}(0)}^{\top} \mathbf{h}(1)
\end{aligned}
$$

A nonlinear simultaneous set of equations does not necessarily have a unique solution. Multiple solutions in this case correspond to different local minima of $L$ and $J$. The set $(2.3 .5 \mathrm{a}-\mathrm{d})$ is solved iteratively in the following manner. A first estimate of the initial state, $\mathbf{x}_{0}(0)$, is obtained. Following Marotzke and Wunsch (1993), we spin-up the model for 250 days and use that final state as our first guess $\mathbf{x}_{0}(0)$. Then Equations (2.3.5a), the model, are used to advance the state vectors to $\mathbf{x}\left(t_{f}\right)$. Equation (2.3.5b) can then be solved for $\mathbf{h}\left(t_{f}\right)$ which then enables one to use Equations $(2.3 .5 \mathrm{c})$, the adjoint of the model, to "advance" the Lagrange multipliers to $\mathbf{h}(1)$. Now, all terms on the right-hand side Equation (2.3.5d) are known and the gradient

$$
\frac{\partial L}{\partial \mathbf{x}(0)}=\frac{\partial J}{\partial \mathbf{x}(0)}
$$

can be computed. Indeed, the reason for computing the Lagrange multipliers through the adjoint model is to be able to compute the gradient of the cost function (Equations (2.3.6)) this way. If they vanish, a minimum has been attained. If not, as is usually the case, this gradient can now be used, via a conjugate gradient minimization routine, to find another initial condition $\mathrm{x}_{n+1}(0)$. The iterative cycle is continued to lower the cost function until convergence criteria are satisfied. Note that in order to lower the cost function as much as possible, we also optimized the surface fluxes which are present in the Lagrange function, Equation (2.3.4), through the data term of the cost function and through the boundary conditions on $\mathcal{G}$, Equation (2.3.2).

As a final comment, let us remark that it if the "information content" of the dataset is "complete" enough, where complete will be explained shortly, it is possible to include unknowns $\mathbf{u}(t)$, open boundary conditions or other unknown control variables for example, into the model, as in $\mathcal{G}[\mathbf{x}(t), \mathbf{u}(t)]$, and add another term into the 
cost function

$$
J^{\prime}=J+\frac{1}{2} \sum_{t=0}^{t_{f}-1} \mathbf{u}(t)^{\top} \mathbf{Q} \mathbf{u}(t)
$$

where $Q$ is a weight matrix representing our statistical "prejudice" about the unknown controls, for instance boundary layer uncertainty. This means that in addition to Equations (2.3.5a-d), with $L^{\prime}$ instead of $L$, a minimum must also satisfy

$$
0=\frac{\partial L^{\prime}}{\partial \mathbf{u}(t)}=\mathbf{Q u}(t)+\frac{\partial \mathcal{G}}{\partial \mathbf{u}(t)}^{\top} \mathbf{h}(t+1), \quad 0 \leq t \leq t_{f}-1 .
$$

In analogy to Equation (2.3.5d), the gradient of Equations (2.3.8) would provide information on how to vary the unknowns $\mathbf{u}(t)$ to find a minimum of $L^{\prime}$.

To understand the information content of the dataset $\mathbf{y}$ with respect to the unknown controls $\mathbf{u}(t)$, we must first recall that the cost function Equation (2.3.4) is a potentially nonlinear function of the $\mathbf{u}(\mathrm{t})$ through the model $\mathcal{G}=\mathcal{G}[\mathbf{x}(t) ; \mathbf{u}(t), \mathbf{y}]$. We expand the cost function in a Taylor series about the minimum $\mathbf{u}=\mathbf{u}_{m}$ with respect to the unknown controls

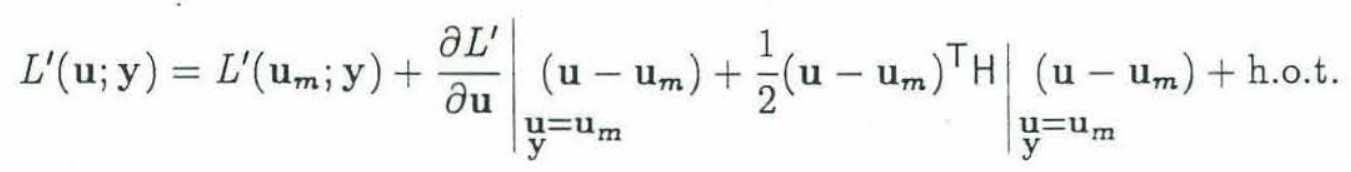

Near the minimum, the gradient nearly vanishes (Equations (2.3.8)), and Equation (2.3.9) becomes

$$
L^{\prime}(\mathbf{u} ; \mathbf{y}) \approx L^{\prime}\left(\mathbf{u}_{m} ; \mathbf{y}\right)+\frac{1}{2}\left[\mathrm{~V}\left(\mathbf{u}-\mathbf{u}_{m}\right)\right]^{\top} \Lambda \mid \begin{array}{|l}
\mathbf{u}=\mathbf{u}_{m} \\
{\left[\mathrm{~V}\left(\mathbf{u}-\mathbf{u}_{m}\right)\right]}
\end{array}
$$

where $\mathrm{H}$, the Hessian or matrix of second partials, in Equation (2.3.9) has been diagonalized, $\mathrm{H}={\mathrm{V} \Lambda \mathrm{V}^{-1}}^{-1}$, in Equation (2.3.10). Note that some authors include the factor of $1 / 2$ from the Taylor expansion into $H$. In analogy to the diagonal weight matrices $W_{D}$ and $W_{S}$ where small errors give rise to large eigenvalues and large errors give rise to small eigenvalues, it is clear from Equation (2.3.10) that large eigenvalues $\lambda_{i}$ of the Hessian will force the corresponding combination of unknowns $(\mathrm{Vu})_{i}$ to be close to the $\left(\mathbf{V u}_{m}\right)_{i}$, meaning that they are well resolved. Continuing the analogy, 
small eigenvalues $\lambda_{j}$ of $\mathrm{H}$ will mask the corresponding residual $\left[\mathrm{V}\left(\mathbf{u}-\mathbf{u}_{m}\right)\right]_{j}$, allowing that residual to become large while leaving the cost function essentially unchanged, meaning that the $\mathbf{u}$ corresponding to these $\lambda_{j}$ are not well resolved by the data $\mathbf{y}$. Thus, it is the size of the eigenvalues of the Hessian $\mathrm{H}$ which convey the completeness of the information content of the data $\mathbf{y}$ for a given model, and data assimilation through the variational adjoint, which strives to transmute the known and widelyavailable datasets into the "golden" unknowns $\mathbf{u}$, can be seen then, because of the Hessian $\mathrm{H}$, to be an informed abstract alchemy of sorts. 


\section{Chapter 3}

\section{Numerical Experiments}

In all experiments, the data weights were chosen to be the inverse of the error covariance matrices, with the errors used as described in section 2.1. Five experiments were performed, varying the eddy diffusivities $\left(K_{H}, K_{V}\right)$ between them. The portion of eddy diffusivity parameter space explored is shown in Figure 3.1. The point labeled "control" is the combination of Marotzke and Wunsch (1993), $K_{H}=10^{7}, K_{V}=1$ $\mathrm{cm}^{2} / \mathrm{s}$ and will be referred to here as Run 0 . Runs A and B explore the parameter space holding $K_{H}=10^{7} \mathrm{~cm}^{2} / \mathrm{s}$ fixed, with the $K_{V}=0.1 \mathrm{~cm}^{2} / \mathrm{s}$ of Run A being towards the lower boundary of the typical range of values of $K_{V}$ found in the literature, but the $K_{V}=10 \mathrm{~cm}^{2} / \mathrm{s}$ of Run B being deliberately chosen at the upper bound of that range. Runs $\mathrm{C}$ and $\mathrm{D}$ held $K_{V}=1 \mathrm{~cm}^{2} / \mathrm{s}$, the value of our control, but decreased $K_{H}$ to examine the conclusions of Böning et al. (1994). In Run C, $K_{H}=5 \times 10^{6} \mathrm{~cm}^{2} / \mathrm{s}$ was used while in Run D, $K_{H}=10^{6} \mathrm{~cm}^{2} / \mathrm{s}$. The cost functions, Equation (2.3.4), for the different experiments are shown in Figure 3.2. The jumps in the values of the cost functions between certain iterations are due to readjustments when restarting the procedure from the final rather than the initial state of the previous iteration, and are to be expected. One noticeable feature of Figure 3.2, however, is that the cost function for Run $\mathrm{D}$, the run with the lowest horizontal eddy diffusivity, is well above the others. Inspecting the components of the cost functions, shown in Table 3.1, one notices the steadiness misfits of both potential temperature and salinity are unusu- 


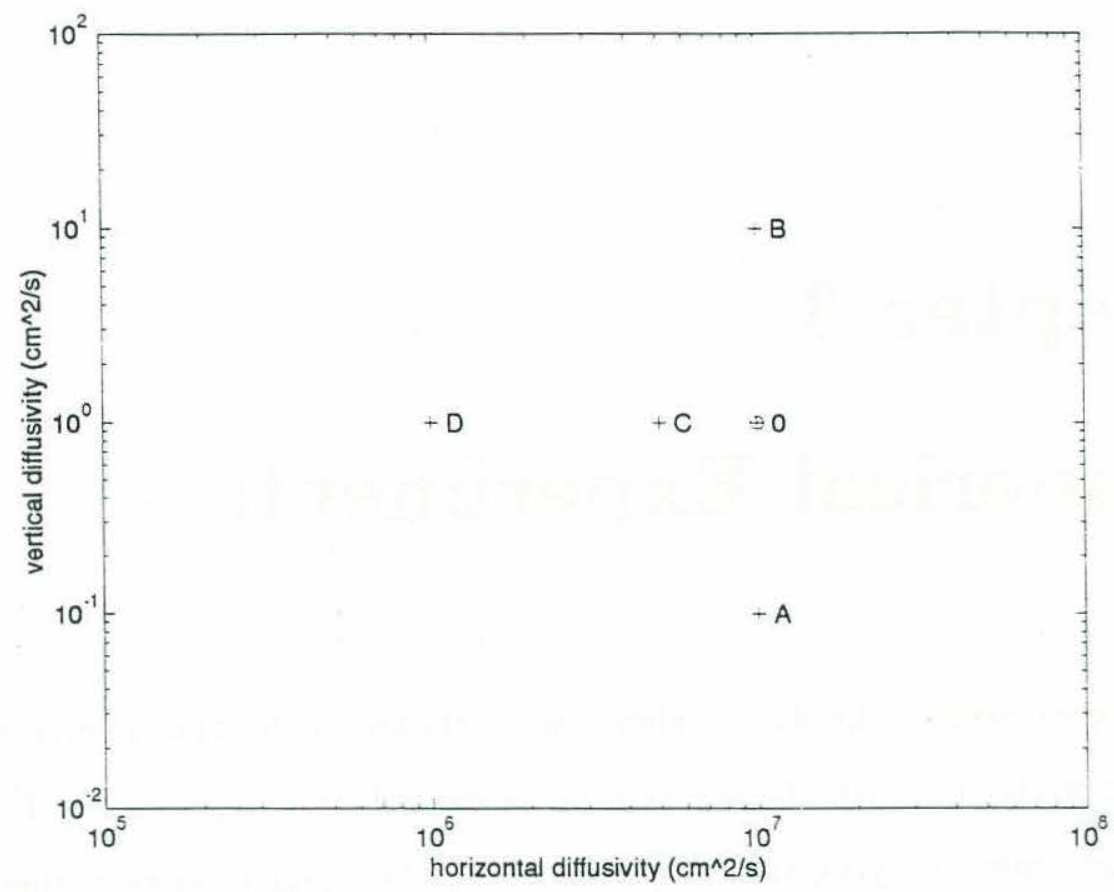

Figure 3.1: Eddy Diffusivity Parameter Space. The choice of Marotzke and Wunsch $(1993),\left(10^{7}, 1\right)$ $\mathrm{cm}^{2} / \mathrm{s}$, is marked as "control." (Note log-log scale.)

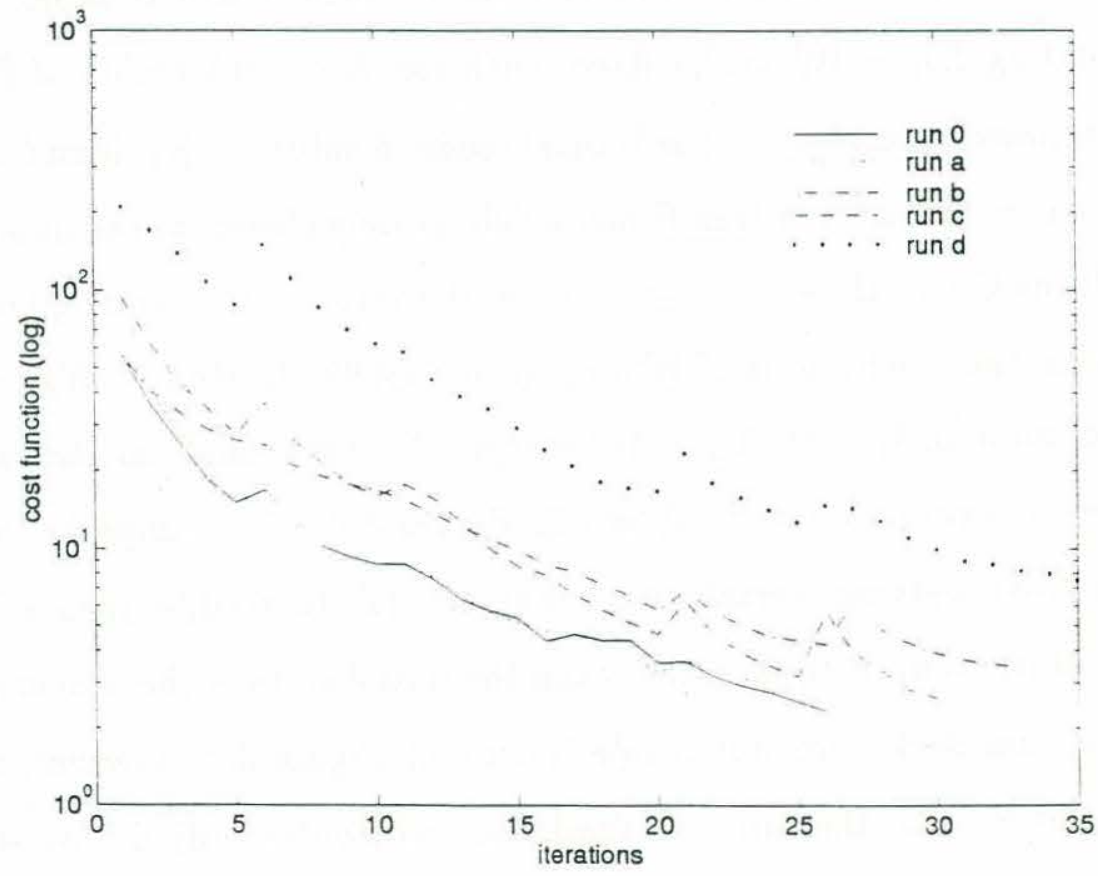

Figure 3.2: Cost Functions of the Experiments. (Note semilog scale.) 


\begin{tabular}{|cc||c||c|cccc|}
\hline $\begin{array}{c}K_{V} \\
\left(\mathrm{~cm}^{2} / \mathrm{s}\right)\end{array}$ & $\begin{array}{c}K_{H} \\
\left(\mathrm{~cm}^{2} / \mathrm{s}\right)\end{array}$ & Run & $\begin{array}{c}\text { total } \\
\text { cost }\end{array}$ & $\begin{array}{c}\text { Levitus } \\
\theta \text { misfit }\end{array}$ & $\begin{array}{c}\text { Levitus } \\
S \text { misfit }\end{array}$ & $\begin{array}{c}\text { steady } \\
\theta \text { misfit }\end{array}$ & $\begin{array}{c}\text { steady } \\
S \text { misfit }\end{array}$ \\
\hline 1 & $10^{7}$ & 0 & 2.34 & 0.54 & 0.32 & 0.82 & 0.66 \\
0.1 & $10^{7}$ & A & 2.44 & 0.54 & 0.32 & 0.85 & 0.74 \\
10 & $10^{7}$ & B & 2.80 & 1.6 & 0.81 & 0.25 & 0.18 \\
1 & $5 \times 10^{6}$ & C & 2.61 & 0.81 & 0.43 & 0.77 & 0.61 \\
1 & $10^{6}$ & D & 6.51 & 1.2 & 0.58 & 2.8 & 1.9 \\
\hline
\end{tabular}

Table 3.1: Components of the Smallest Cost Function of Each Experiment.

ally large in Run D, while the climatological misfits are not as unusual. This suggests that although the minimization has found a solution which is roughly as consistent with the data as in the other experiments, in Run D the dynamical part of the cost function is not as consistent. A plausible explanation is that the transients damped out in the other experiments are not damped out here. Therefore that the smallest $K_{H}$ which completely damps out numerical artifacts for the coarse resolution grid lies between $10^{6}$ and $5 \times 10^{6} \mathrm{~cm}^{2} / \mathrm{s}$ for $K_{V}=1 \mathrm{~cm}^{2} / \mathrm{s}$. Since Run D lies near the threshold for the onset of numerical instabilities however, we should not yet rule it out as totally corrupted by numerical artifacts.

\subsection{Residuals}

We begin by discussing the residuals, $T_{\text {base }}-T_{\text {final }}$ where the tracers $T$ are either $\theta$ or $S$ and $T_{\text {base }}$ is the particular residual ( $T_{\text {data }}$ or $T_{0}$ for the steady residual), for the control run, Run 0. Figure 3.3 shows the the horizontally-averaged residuals for each of the 24 vertical levels normalized by the level-averaged standard deviation. Figure 3.3a shows the optimization of Run 0 is rather consistent with the hydrographic climatology, in every level falling within the average expected error of the data for that level. Figure 3.3b shows that the optimization's steadiness, while not as good as the hydrographic climatology, is acceptable. At mid-depth both model fields and at one or two levels at depth the potential temperature field slightly exceed one level- 
(a)

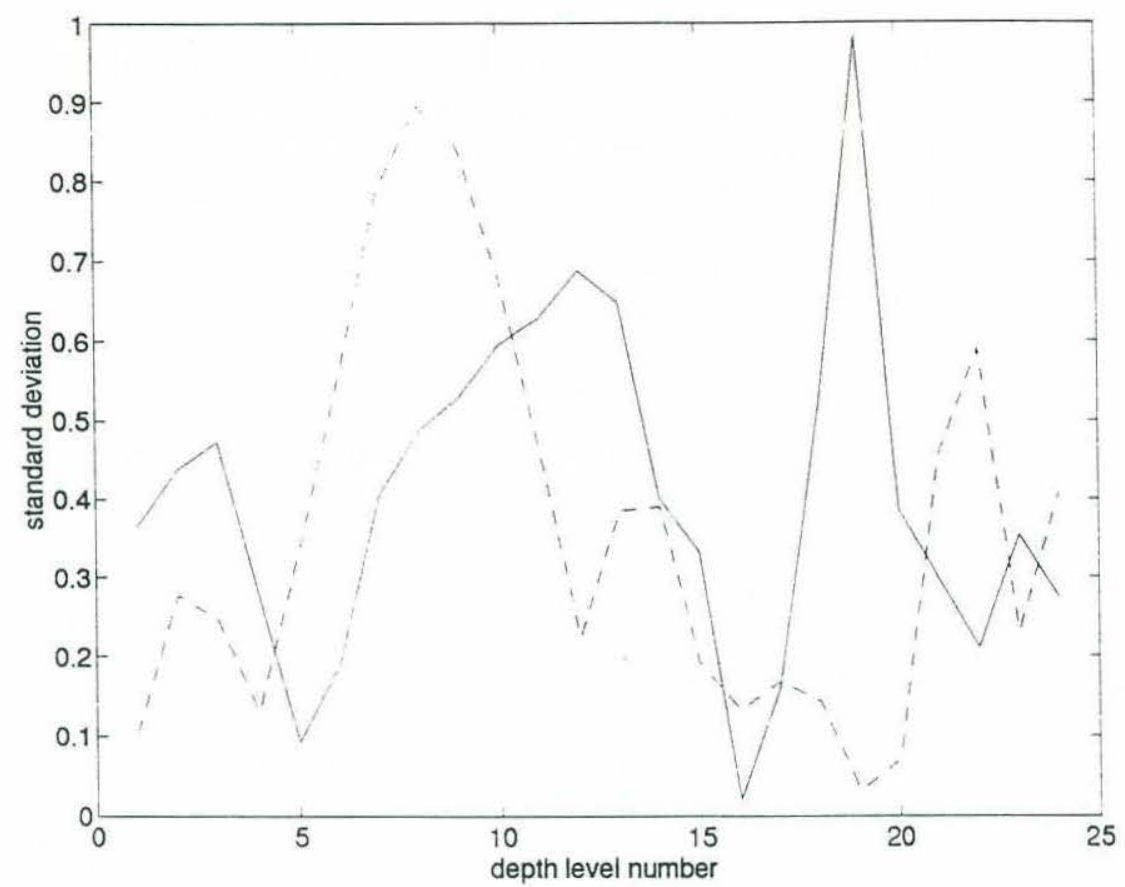

(b)

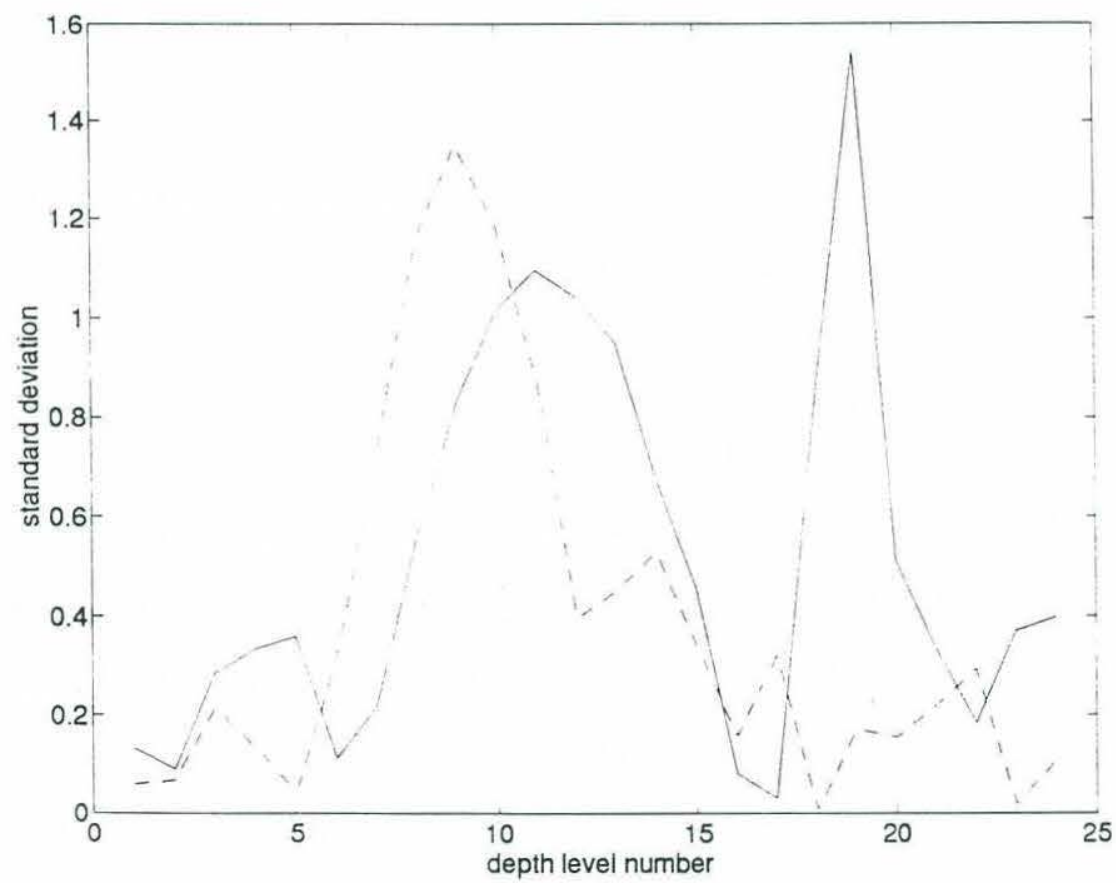

Figure 3.3: Normalized Horizontally-averaged Residuals for Run 0, (a) Data Misfit Residuals, and (b) Steadiness Misfit Residuals. (Level 0 is the surface.) The $\theta$ curves are solid, and the $S$ curves are dashed. 
averaged standard error. Figures 3.3 do correlate well with the parts of the cost function in Table 3.1 where the hydrographic misfits are smaller than the steadiness misfits with the exception of Run B, and the salinity behaves slightly better than the potential temperature.

Figure $3.4 \mathrm{a}$ shows the temporal drift residual of the potential temperature extrapolated over the steadiness time $\tau=10$ years for the control run at the first model level, i.e. $\left(\theta_{f}-\theta_{0}\right) \tau / t$ where $\theta_{0}$ is the initial potential temperature, $t=500$ days is the integration time, and $\theta_{f}$ is the potential temperature at time $t$. The magnitudes of the temporal drifts here are larger than those of Marotzke and Wunsch (1993) Experiment 1, by almost one order of magnitude. They are of the same order as their Experiment 3, which is the closest to our control run, and the drifts of large magnitude are mostly clustered around the southeastern part of the subtropical gyre. This residual is not white noise, but its structures are not strongly coherent either. Even though the steady misfit components of the cost function in Table 3.1 show that we have reached a minimum, we are evidently in the same situation of Marotzke and Wunsch (1993), viz. the steady state found is not simultaneously consistent with both the Levitus climatology and the surface fluxes used. At the cooler lower levels,

the magnitude of the temporal drifts decreases (Figures $3.4 \mathrm{~b}$ and c). It is interesting that although level 17, Figure 3.4b, has an extremely low magnitude, it is overall negative. While the residuals shown in Figure $3.4 \mathrm{~b}$ are the absolute values of the temporal drift, the temporal drift of level 17 is negative. Figure $3.4 \mathrm{c}$, the level with the largest normalized steady residual $(+1.54)$ does seem to be quite coherent with a larger positive region south of Greenland.

\subsection{Basin-wide results}

Before focussing on the localized upwelling region slopeward of the Gulf Stream, let us first examine the basin-wide solution. We begin with a brief survey of the Levitus (1982) climatology. Figures 3.5 show smooth averaged isotherms, typical 
(a)

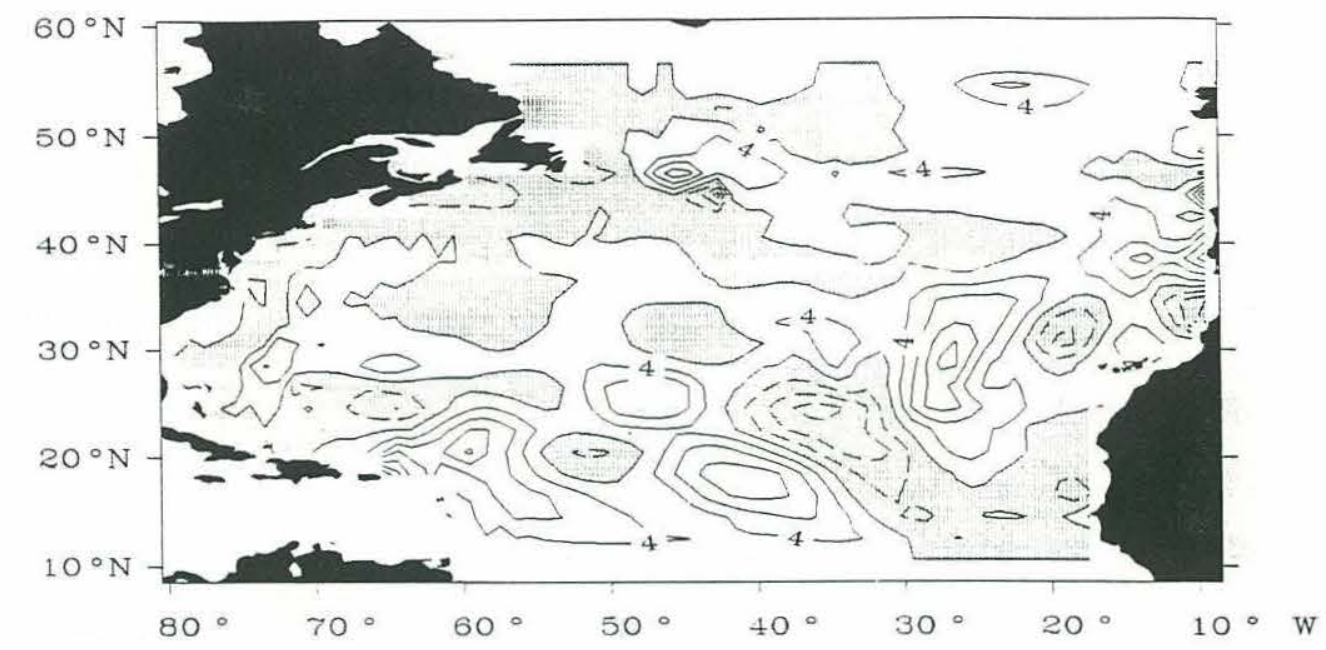

(b)

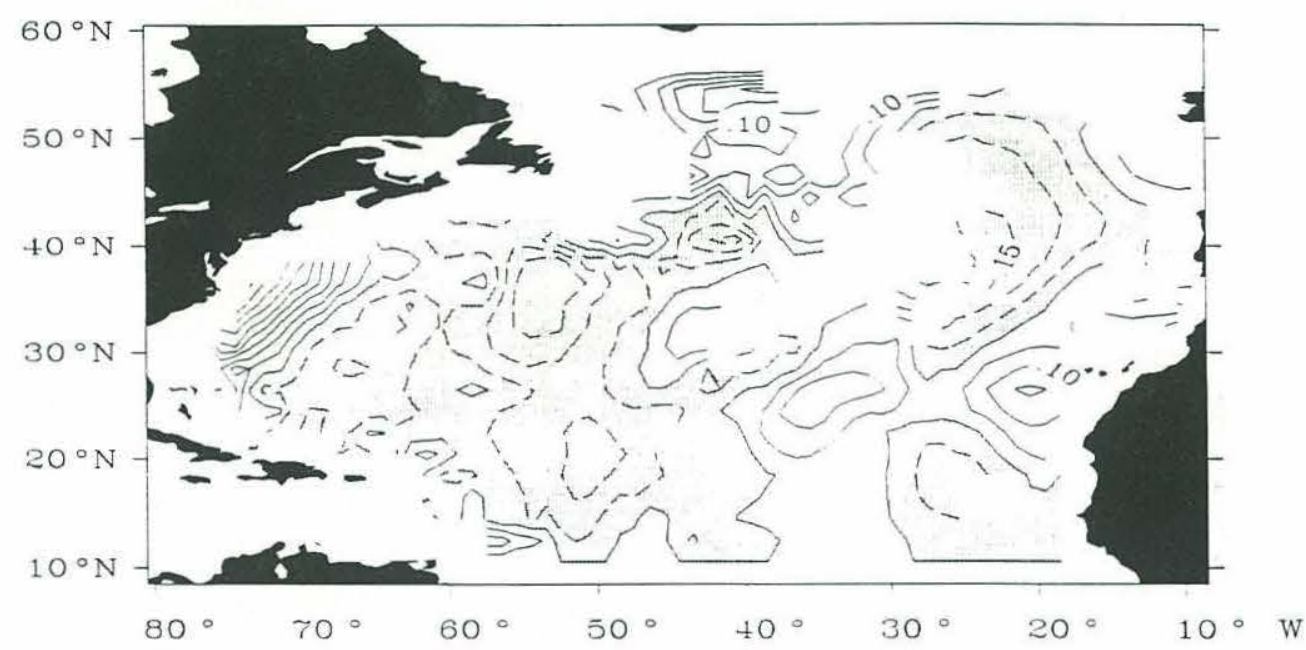

(c)

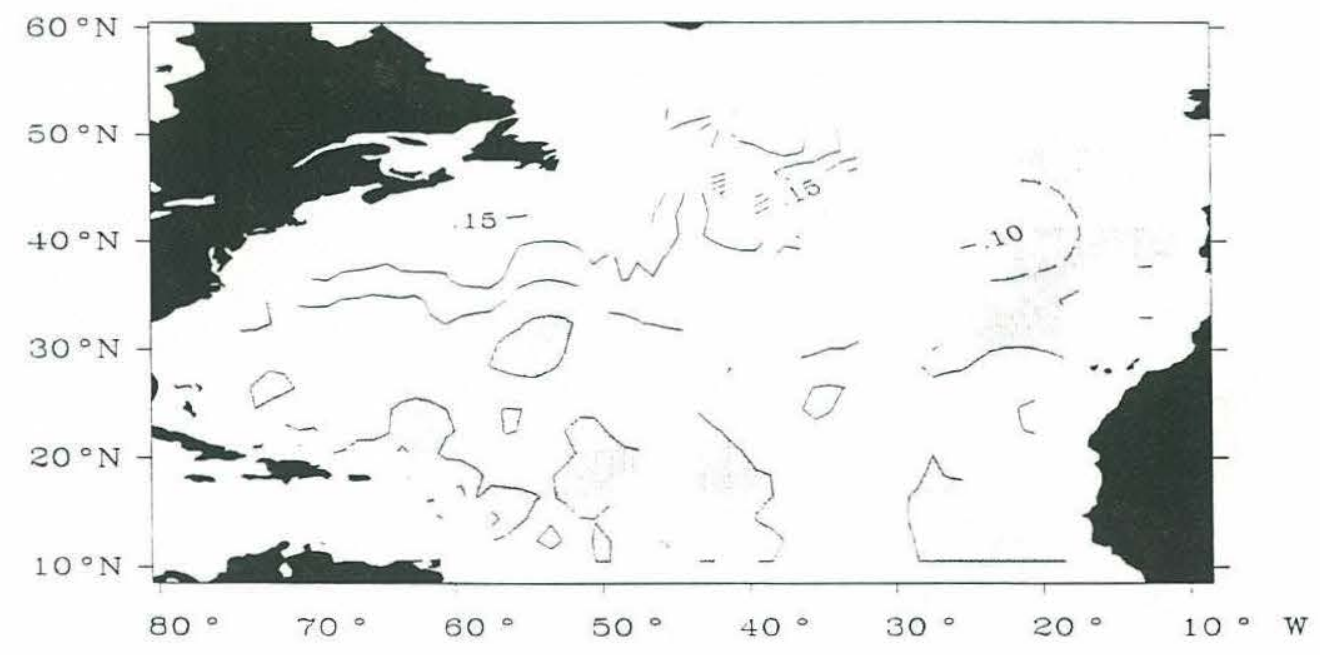

Figure 3.4: Temporal Drift Residuals of Potential Temperature Extrapolated Over Steadiness Time $\tau=10$ Years of Run 0 at (a) First model level (interval $4^{\circ}$ ), (b) Level 17 (low averaged misfit, interval $0.5^{\circ}$ ), (c) Level 19 (high averaged misfit, interval $0.5^{\circ}$ ). Negative contour levels dashed. Negative regions shaded. 
(a)

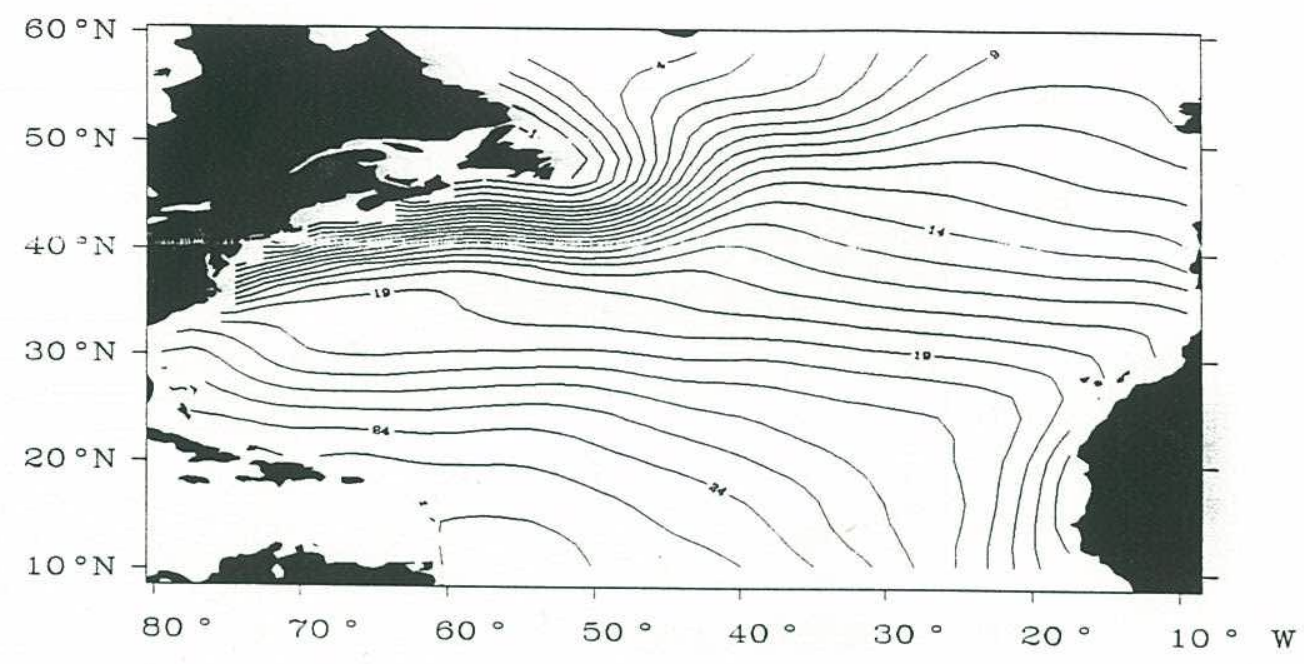

(b)

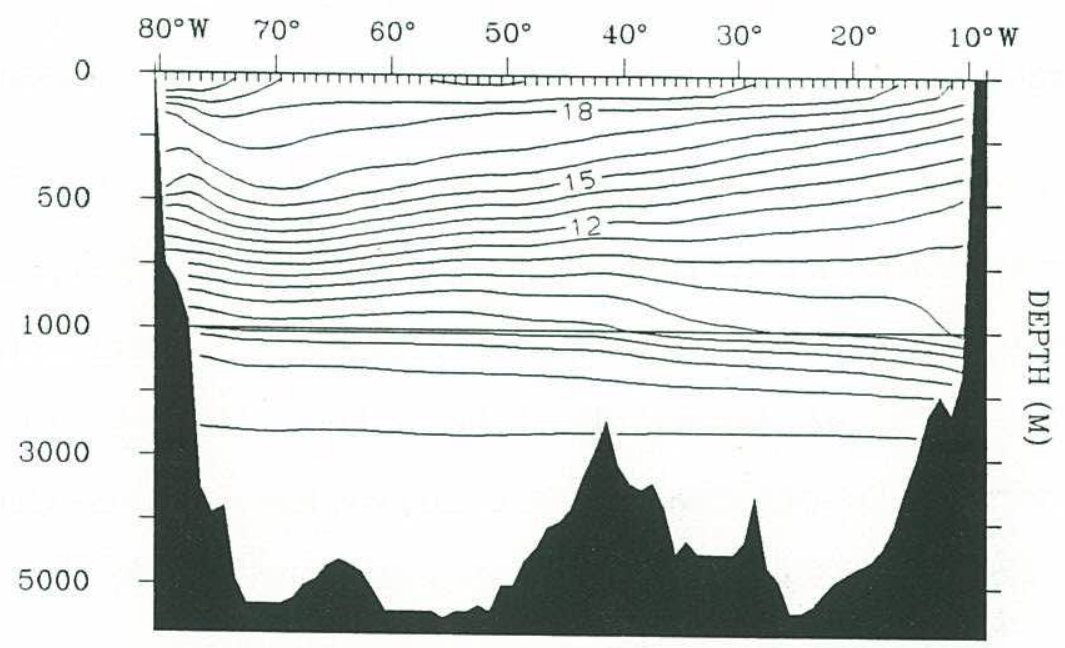

(c)

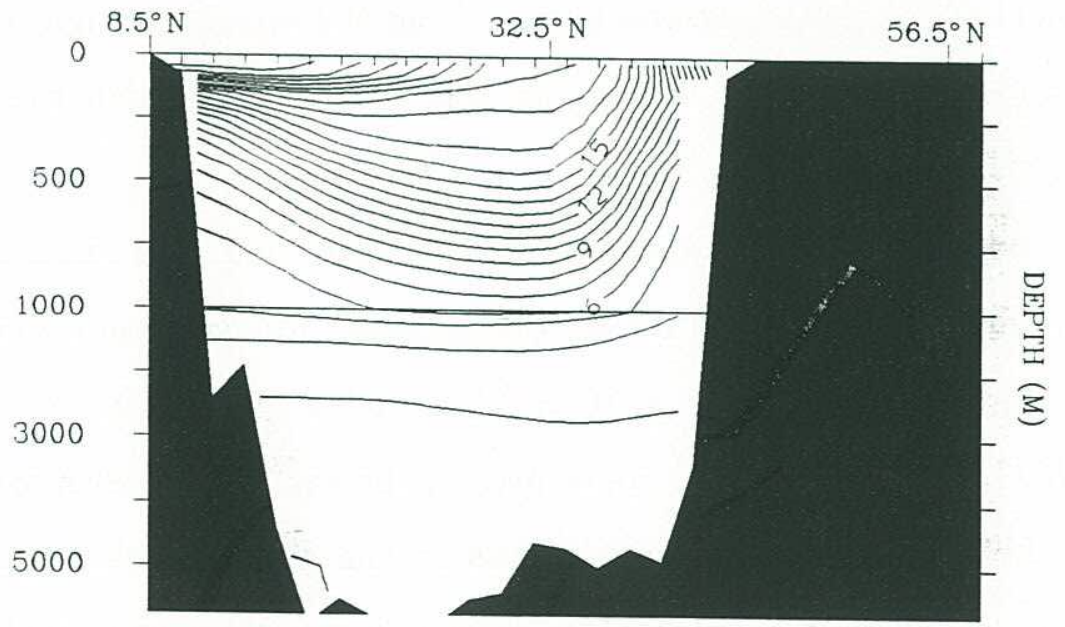

Figure 3.5: Levitus Potential Temperatures (a) at the First Model Level (25 m), (b) Zonal section across $30.5^{\circ} \mathrm{N}$, and (c) Meridional section across $60.5^{\circ} \mathrm{W}$. (interval $1^{\circ}$ ) 


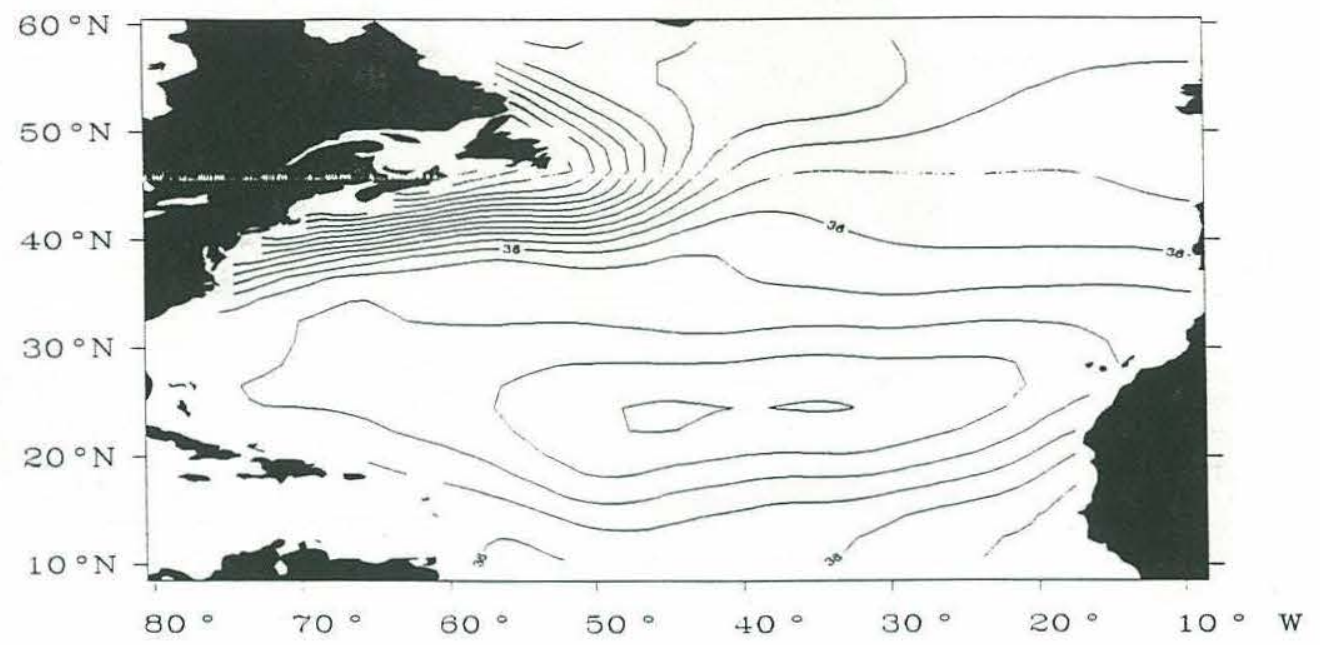

Figure 3.6: Levitus Salinity (psu) at First Model Level (25 m, interval 0.3).

of climatologies. In Figure 3.5a, at the first model level, the Gulf Stream itself is extremely smeared with a cross-section of about $900 \mathrm{~km}$, and a broad North Atlantic current turns northward south of Greenland. Figure 3.5b, a zonal section of temperature at $35.5^{\circ} \mathrm{N}$, shows an eastward tilt of the isotherms throughout the basin and a stronger westward tilt toward the western boundary, hinting of the Gulf Stream System. Figure $3.5 \mathrm{c}$, a meridional section of temperature at $60.5^{\circ} \mathrm{W}$ shows downwelling in the northern regions, by the outcropping isotherms, and a deeper thermocline in the subtropical gyre which shallows approaching the equator. Figure 3.6 shows the climatological salinity (psu) at the model subsurface level, with the usual interior pool of high salinity in the tropics.

We begin our discussion of the optimizations with the series Run A, Run 0, Run B, throughout which $K_{H}=10^{7} \mathrm{~cm}^{2} / \mathrm{sec}$ and $K_{V}$ increases an order of magnitude from $K_{V}=0.1$ in Run A to $K_{V}=10 \mathrm{~cm}^{2} / \mathrm{sec}$ in Run B. Figures 3.7 , starting from the lowest $K_{V}$ value, show the temperatures at the first model level for the series. In addition to the rich structures reconstructed by the dynamics through the nonlinear optimization over the smoothed climatology (Figure 3.5a) that includes a tighter and more realistic Gulf Stream, temperatures are almost everywhere cooler than the data, except near the Caribbean in Run A and especially Run B. Although winter 
(a)

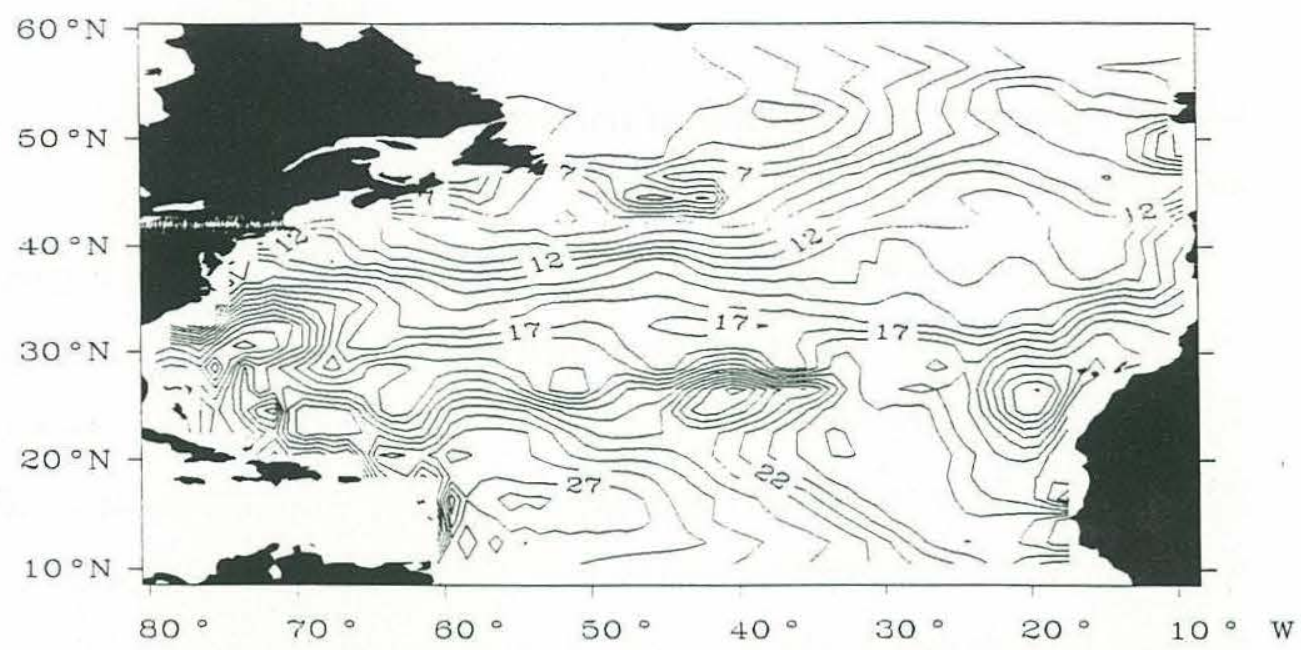

(b)

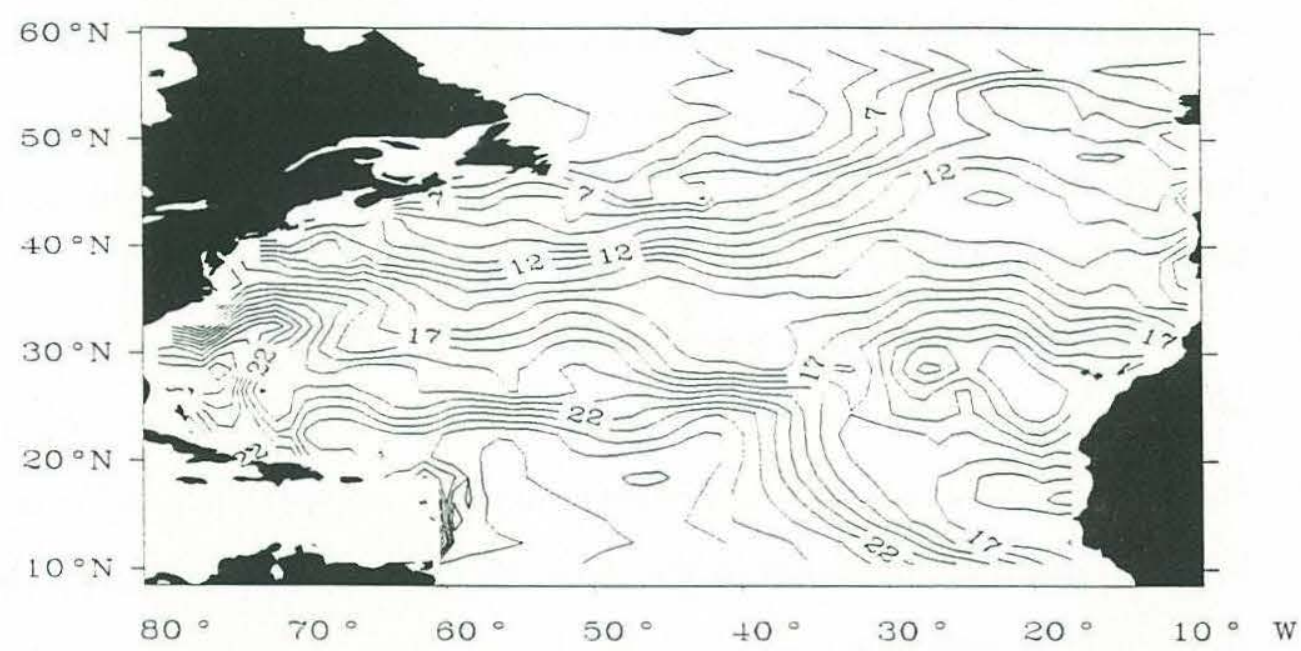

(c)

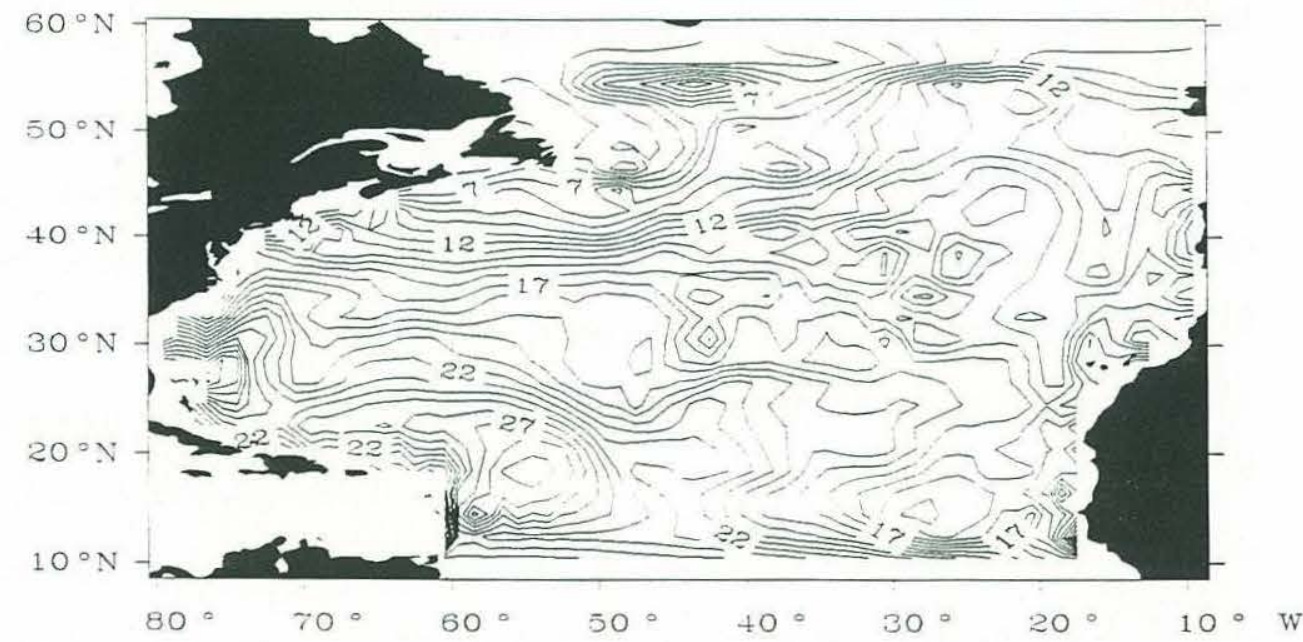

Figure 3.7: Potential Temperatures at $25 \mathrm{~m}$ depth for (a) Run A, (b) Run 0, and (c) Run B. (interval $1^{\circ}$ ) 
climatologies are used, the model itself still has a cold bias as observed by Marotzke and Wunsch (1993).

Figures 3.8 show the zonal sections corresponding to Figure 3.5b. In addition to the generally lower temperatures and the tighter and stronger Gulf Stream front in the western boundary compared to the original data, we see an interesting progression. As we move up the page, from higher to lower vertical diffusivity $K_{V}$, we notice the isotherms become compressed with stronger gradients in the layer between 500 and $1000 \mathrm{~m}$ depth, the layer of the main thermocline. This is not surprising since by choosing a value of $K_{V}$, we make a tremendous statement about diapycnal mixing. The force of this statement is clear in Figures 3.8 showing that the higher vertical diffusivity allows more downward heat diffusion from the warmer surface layers smearing the vertical gradients in the upper $1000 \mathrm{~m}$.

Figures 3.9 , the meridional sections of $\theta$ at $60.5^{\circ} \mathrm{W}$, show an extended region of isotherm outcropping around $40^{\circ} \mathrm{N}$, and a second region of isotherm outcropping near the equator absent in the climatology, Figure 3.5c. Run A, with the lowest $K_{V}$, has the strongest gradients in the main thermocline (Figure 3.9a). We do not show the salinities reconstructed through the optimization as they resemble the data as indicated by the rather small values of the salinity data misfit component of the cost function (Table 3.1).

Figures 3.10 show the zonally averaged meridional mass transport for the series. In Figures 3.10a and $\mathrm{b}$ we have the familiar pattern of a NADW cell extending from the convection region of the polar seas throughout the basin and an abyssal counter-circulating Antarctic Bottom Water (AABW) cell at the equatorward edge. However in Figure 3.10c we see a dramatically dwarfed NADW cell, which, though it has a realistic $18.4 \mathrm{~Sv}\left(1 \mathrm{~Sv}=10^{6} \mathrm{~m}^{3} / \mathrm{s}\right)$ maximum overturning, does not extend further south of $35^{\circ} \mathrm{N}$ because is almost engulfed by an enormous AABW cell with an even stronger maximum overturning of $26.4 \mathrm{~Sv}$. It is clear that the choice $K_{V}=10$ $\mathrm{cm}^{2} / \mathrm{s}$ is too high as it produces quite unrealistic features in the optimization. 
(a)

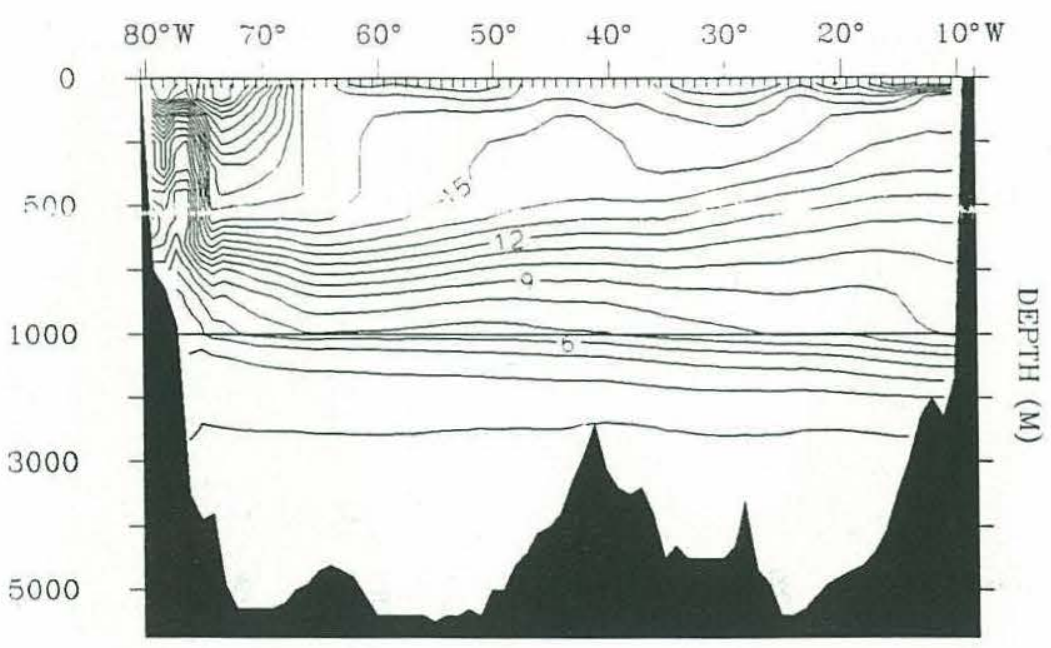

(b)

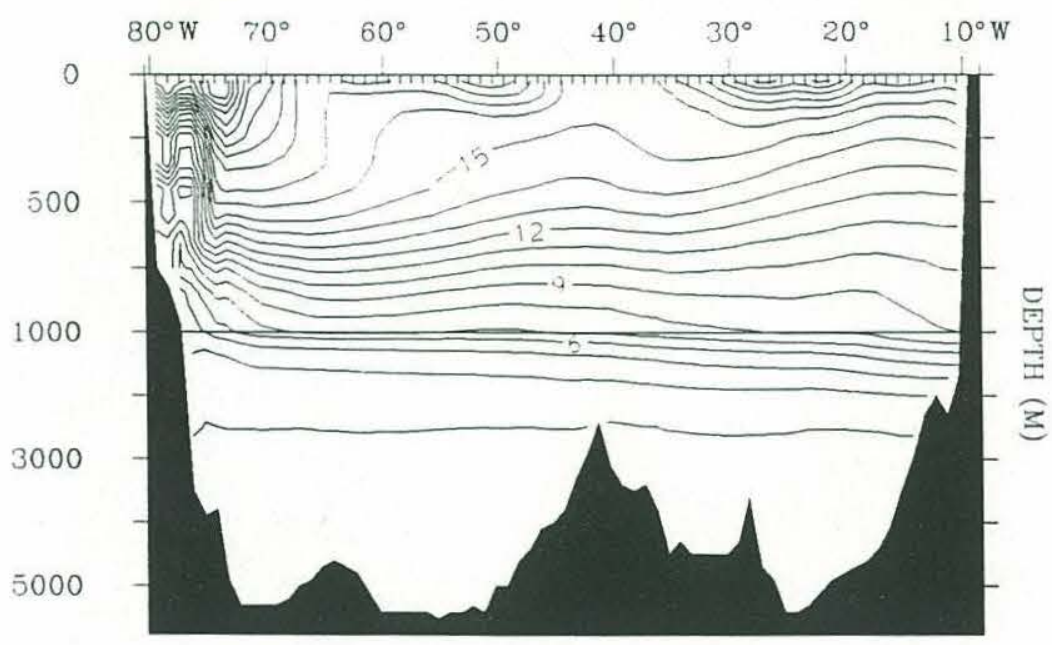

(c)

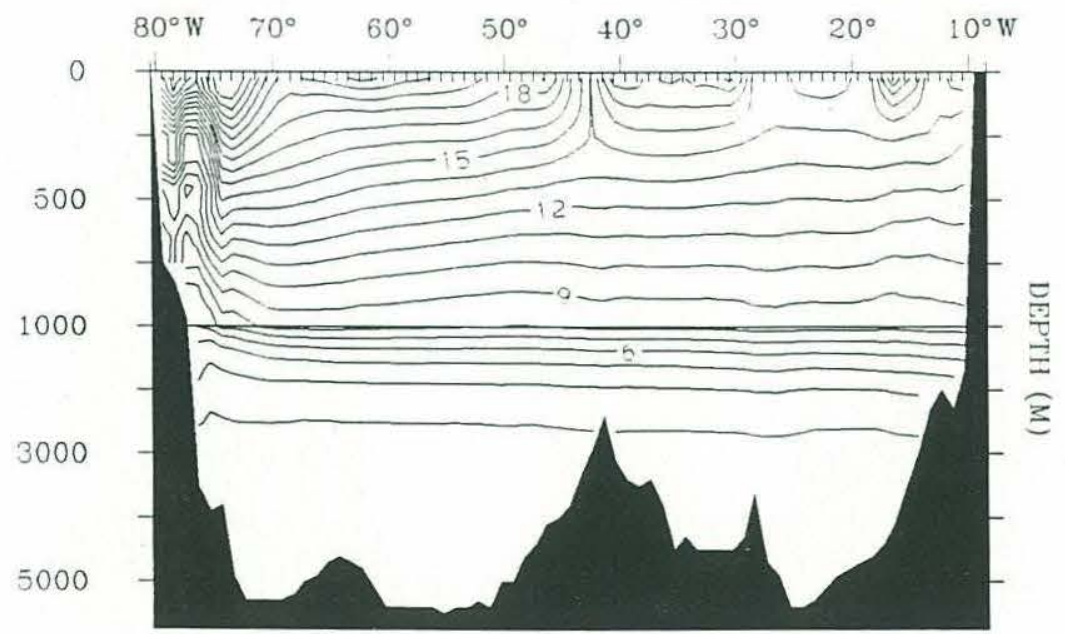

Figure 3.8: Zonal Section of Potential Temperature across $30.5^{\circ} \mathrm{N}$ for (a) Run A, (b) Run 0, and (c) Run B.(interval $1^{\circ}$ ) 
(a)

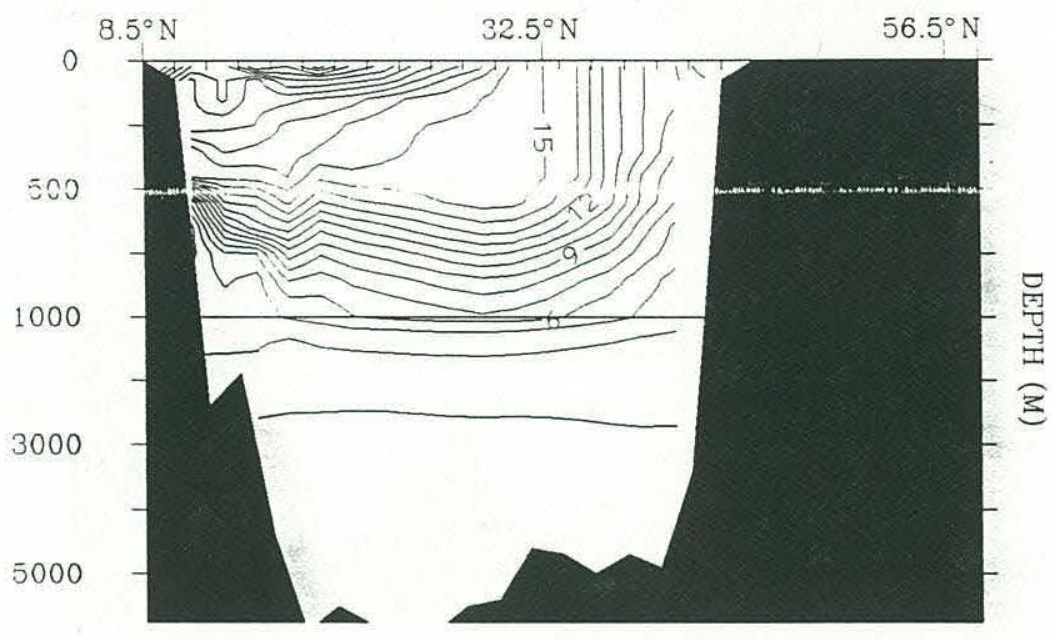

(b)

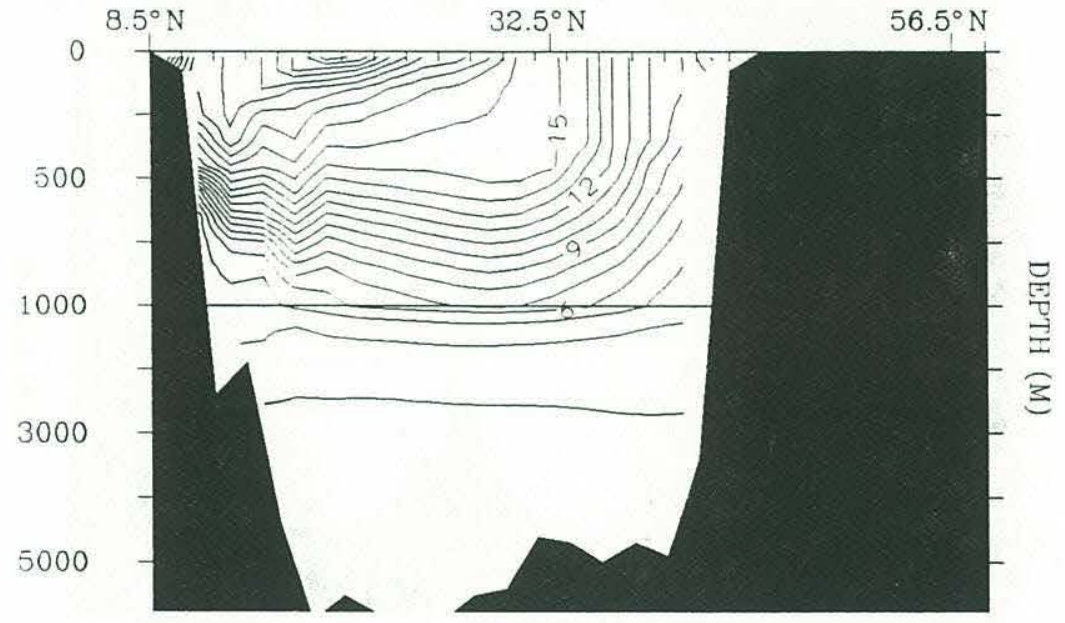

(c)

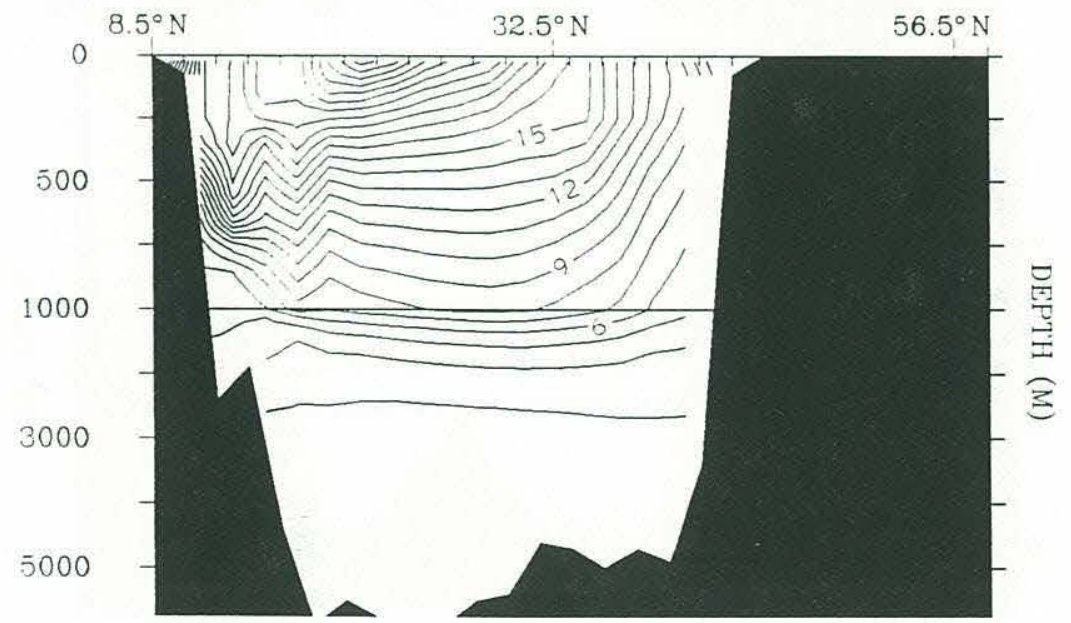

Figure 3.9: Meridional Section of Potential Temperature across $60.5^{\circ} \mathrm{W}$ for (a) Run A, (b) Run 0 , and (c) Run B. (interval $1^{\circ}$ ) 
(a)

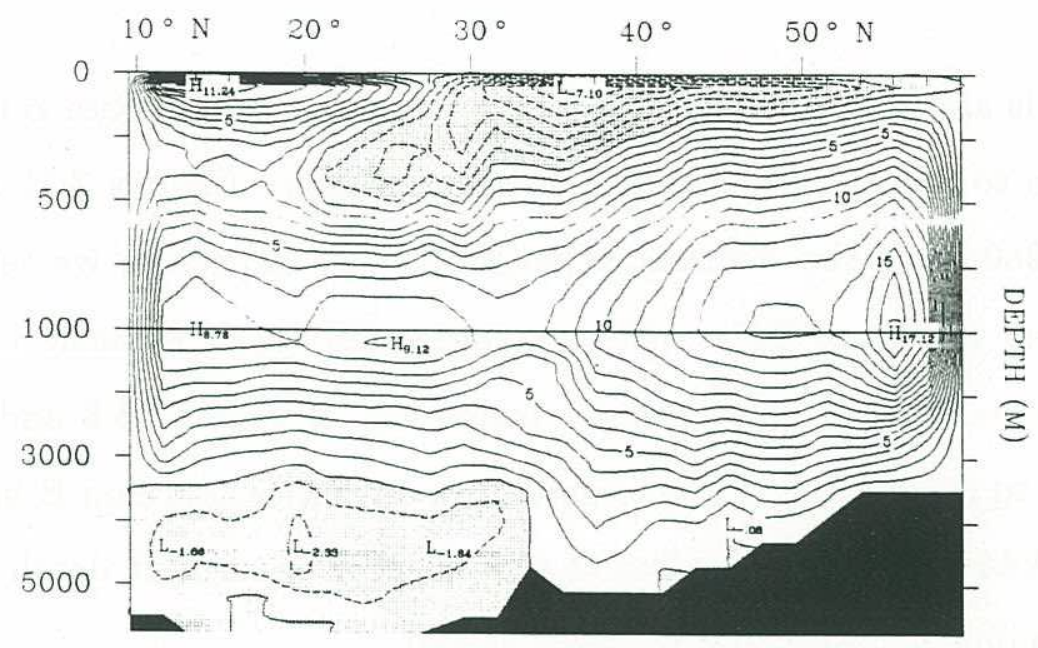

(b)

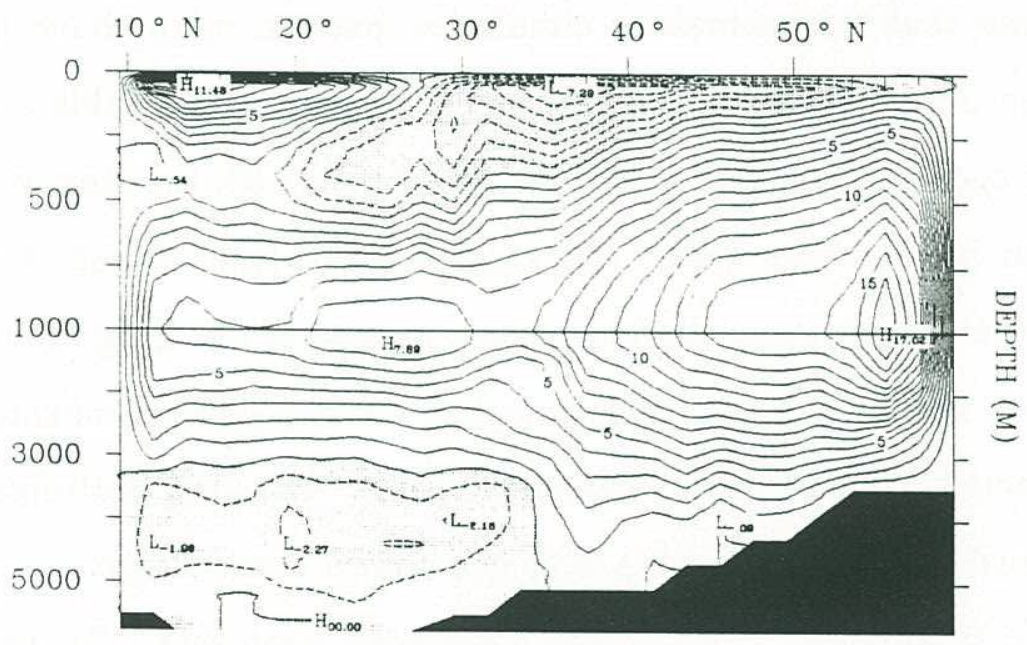

(c)

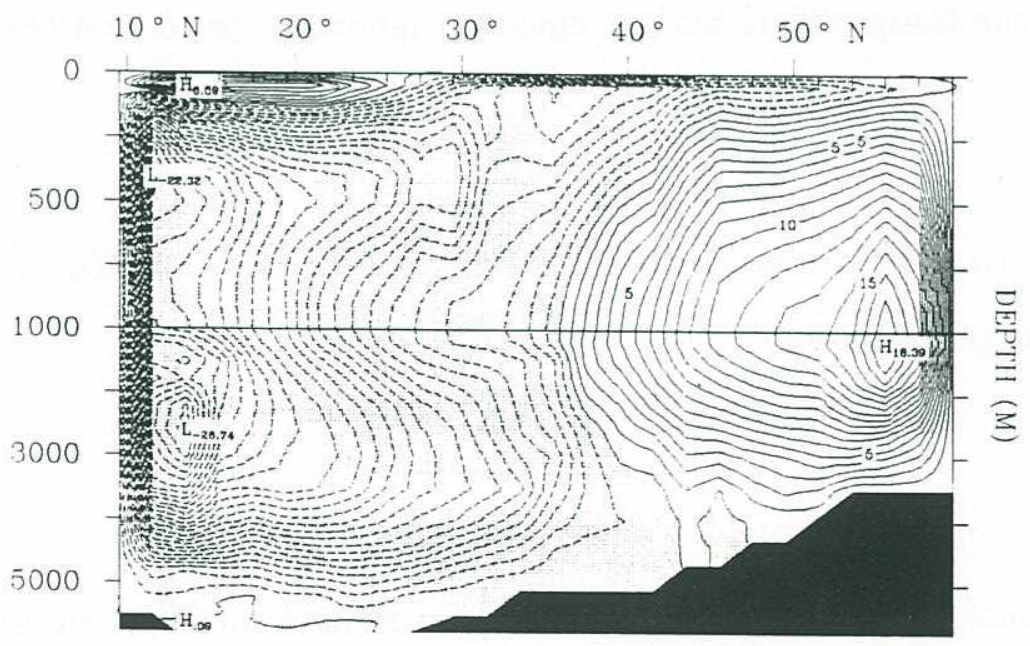

Figure 3.10: Meridional Mass Transport for (a) Run A, (b) Run 0, and (c) Run B. (interval $1 \mathrm{~Sv}$, negative contours dashed, negative regions shaded) 
It is also clear, now, why the entire water column in Run B is not uniformly warmer due to increased downward diffusion of heat. Figures 3.11 show a vertical section at $950 \mathrm{~m}$ in the different experiments. As expected, we see rather higher temperatures in Figure 3.11c with the entire mid-depth Atlantic interior filled by a relatively warm pool of $8^{\circ}$ water. Inspection of Figures 3.8 and 3.9 show that below $2500 \mathrm{~m}$ there is not much temperature difference. As Run B has an enormous upwelling AABW cell, we see that the lower temperatures at depth are maintained by the upwelling of cold water due to that cell.

Note that an anomalous circulation pattern might have been anticipated by careful scrutiny of the components of the cost function, Table 3.1. Although the value of the cost function as a whole is a reasonable 2.80 , the steady misfits are much smaller than in the other cases, less than those of Runs 0 and A by more than a factor of three. These unusually low values, instead of reducing the total value of the cost function, mask the higher climatological $\theta$ and $S$ misfits, meaning that although the cost function converged to a reasonable total value, the optimization produced a solution which was rather at-odds with the known climatology.

We now examine the zonally averaged heat flux. To be specific, let us reconsider the temperature budget equation ignoring convection (Equation (2.2.1b))

$$
\frac{\partial \theta}{\partial t}=-\nabla \cdot(\mathbf{v} \theta)+\nabla \cdot(K \nabla \theta),
$$

where $\mathbf{v}=(u, v, w)$ is the three dimensional velocity, $\nabla=\left(\partial_{x}, \partial_{y}, \partial_{z}\right)$ is the three dimensional gradient, and

$$
\mathrm{K}=\left(\begin{array}{ccc}
K_{H} & 0 & 0 \\
0 & K_{H} & 0 \\
0 & 0 & K_{V}
\end{array}\right)
$$

is the diagonal diffusivity tensor. Integrating Equation (3.2.1) we have

$$
\iiint d^{3} V \frac{\partial \theta}{\partial t}=\iiint d^{3} V \nabla \cdot(-\mathbf{v} \theta+K \nabla \theta) .
$$


(a)

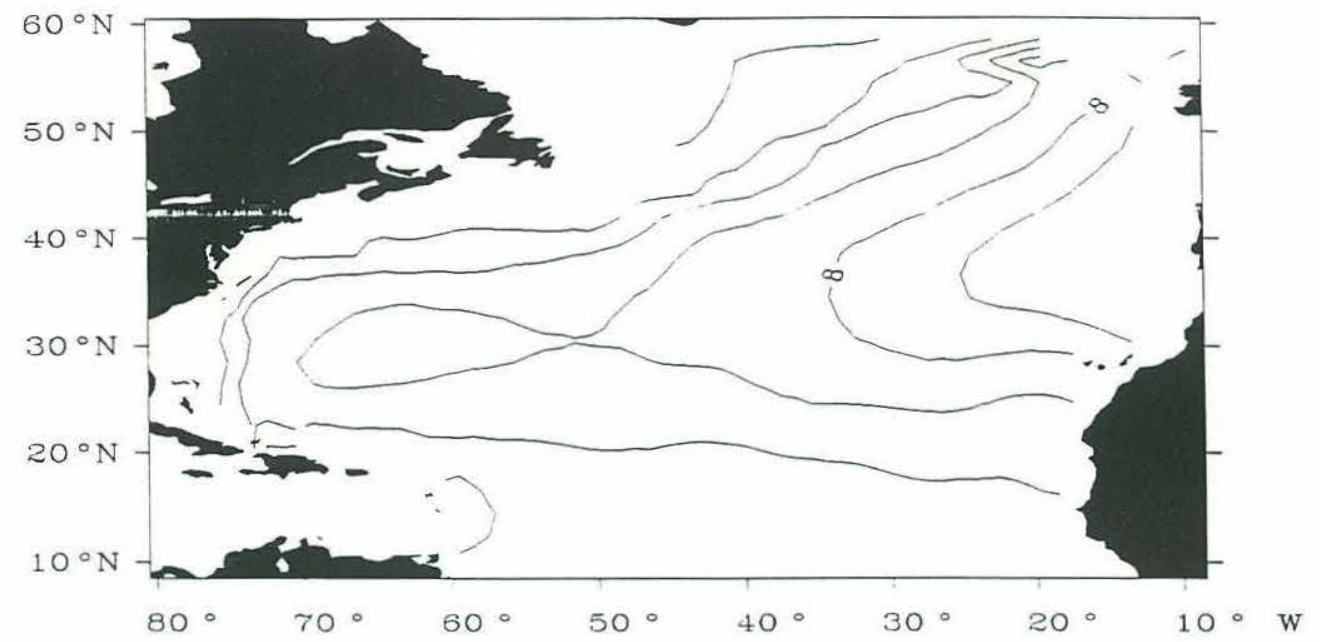

(b)

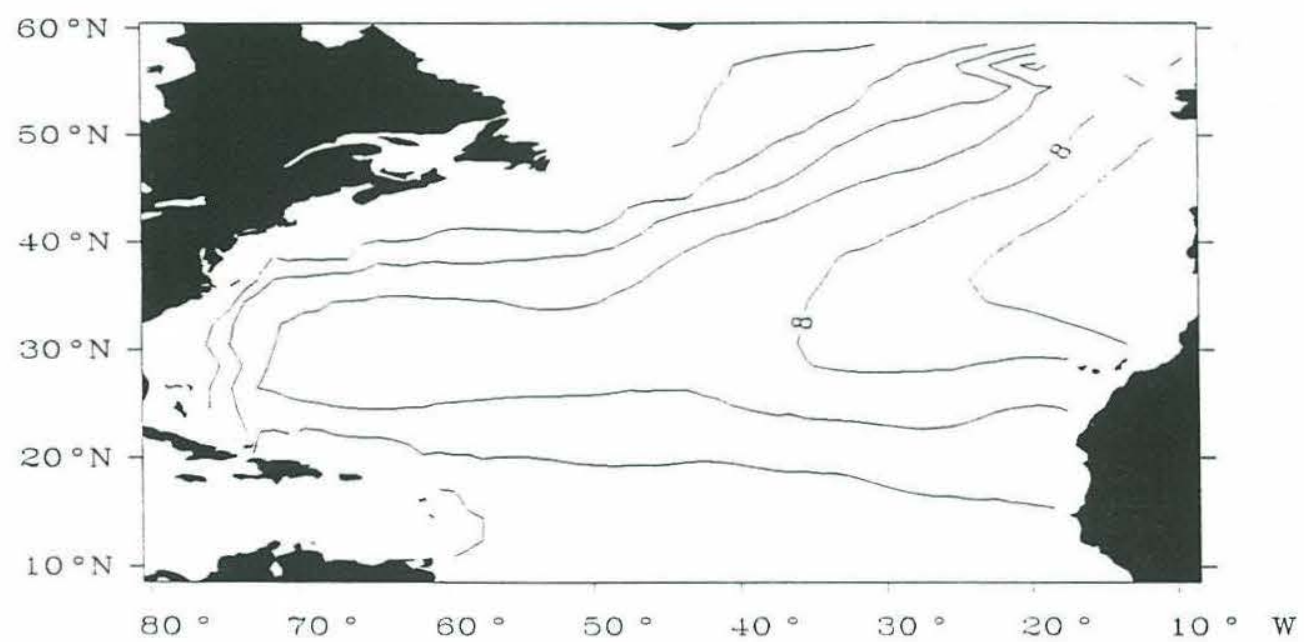

(c)

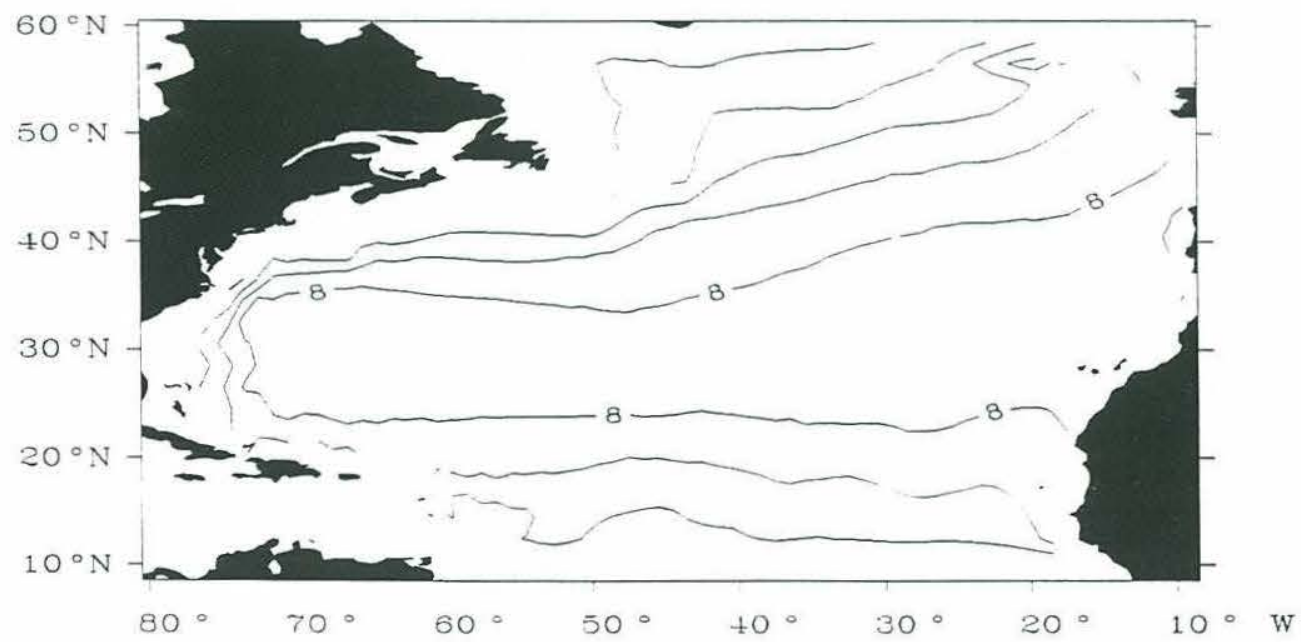

Figure 3.11: Potential Temperature at $950 \mathrm{~m}$ for (a) Run A, (b) Run 0, and (c) Run B. (interval $\left.1^{\circ}\right)$ 


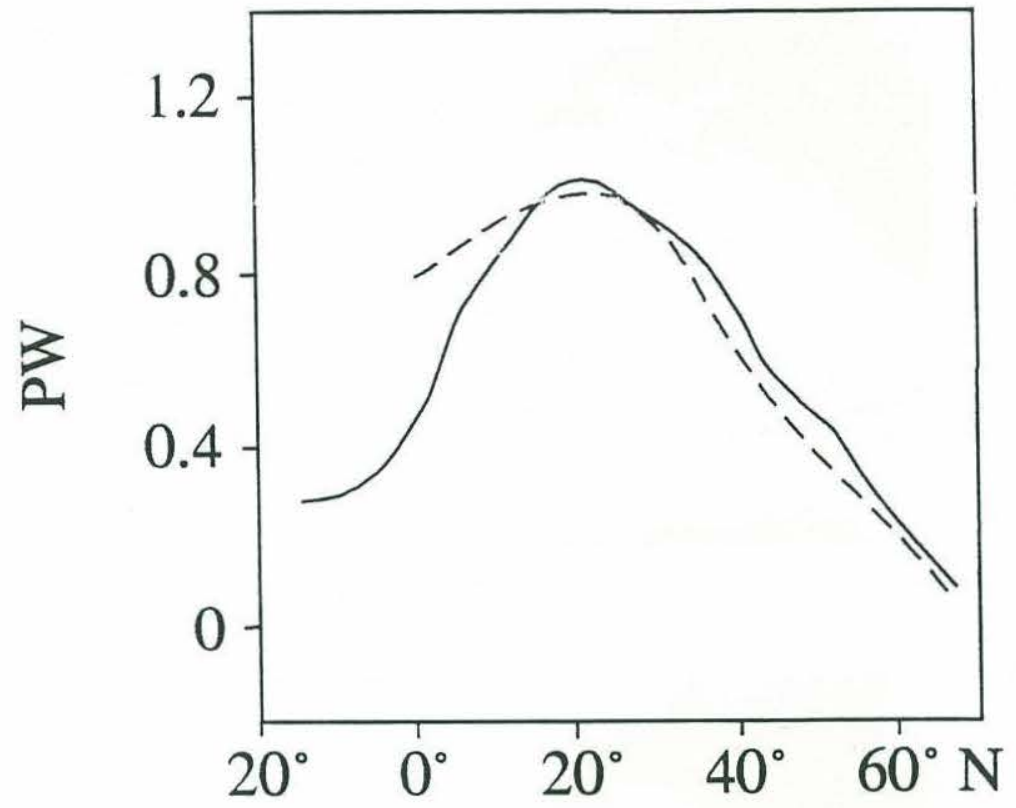

Figure 3.12: Observed Northward Transport of Heat from Isemer et al. (1989) dashed line, and Trenberth and Solomon (1993) solid line. (after Böning et al. 1994)

We now apply the Gauss divergence theorem to the right-hand side of Equation (3.2.2) with $\mathbf{S}$ as the outward-oriented surface bounding $V$ which gives

$$
\iiint d^{3} V \frac{\partial \theta}{\partial t}=-\oiint d^{2} \mathbf{S} \cdot \mathbf{F},
$$

with the heat flux vector

$$
\mathbf{F}=\mathbf{v} \theta-K \nabla \theta .
$$

Therefore, the northward flux of heat $H^{y}$ across a latitude circle in the ocean is

$$
H^{y}=\iint d^{2} \mathbf{S}^{y} \cdot \mathbf{F} / S^{y}=\overline{v \theta}-K_{H} \overline{\theta_{y}}
$$

where $\mathrm{S}^{y}$ is the surface stretching across the basin at that latitude circle whose normal points in the $y$-direction, $S^{y}$ is the area of that surface, and the overbar $(\overline{)}$ denotes a zonal and depth average. Note that observations (Hall and Bryden (1982), Isemer et al. (1989) and Trenberth and Solomon (1993)) report the advective heat flux $\overline{v \theta}$, but do not report the diffusive contribution $K_{H} \overline{\theta_{y}}$, Figure 3.12 . 
Figure 3.13 shows the heat transports for the series. The labeling of the curves corresponds to Fquation (3.2.3) as

$$
\mathrm{TOT}=\mathrm{ADV}+\mathrm{DIF} .
$$

Note that the $\overline{v \theta}$ and $-K_{H} \overline{\theta_{y}}$ curves in Figure 3.13 are suppressed in the latitudes of the Caribbean open boundary conditions since they cannot be rigorously defined in regions where the circulation is not strictly mass conserving. In those latitudes the contribution of the Carribean outflow is crudely taken into account by adding terms of the form $Q_{F} U_{P} / U_{F}$ to the mid-ocean temperature flow following Marotzke and Wunsch (1993). $U_{P}$ is the volume transport through the passages into the Caribbean, and $U_{F}$ and $Q_{F}$ are the volume transport and temperature transport, respectively, through the Florida Straits. It is hardly surprising that Figure 3.13c is quite different from the two very similar patterns of Figures 3.13a and b. The NADW cell of Run B does still transport a miniscule amount of heat northward, but southward of $30^{\circ} \mathrm{N}$, the $\mathrm{AABW}$ cell dominates, making the total heat transport equatorward. It is interesting to note that, although in absolute terms there is little difference, outside of the sponge layers, Run A (Figure 3.13a) uniformly transports more heat poleward than the control run (Figure $3.13 \mathrm{~b}$ ). The most likely explanation is simply that Run A is more highly stratified than Run 0 (as noted earlier Figures 3.8a, b, Figures 3.9a, and b), and therefore, although the circulation features are substantially the same, the circulation in Run A crosses more fronts per unit distance. Finally, note that the eddy contribution to the meridional heat flux is roughly unchanged throughout the series (the vertical scale in Figure 3.13c is compressed.).

Table 3.2 summarizes the basin-wide aspects of all of the Runs, including $\mathrm{C}$ and $\mathrm{D}$ which have not yet been discussed, and includes the corresponding quantities of Experiment 1 of Marotzke and Wunsch (1993) for comparison. Our control run, with the same parameter choice, differs from theirs. As mentioned earlier, we use different potential temperature and salinity climatologies, augment their one-pass convective adjustment scheme, and have included surface fluxes into the cost function. 
(a)

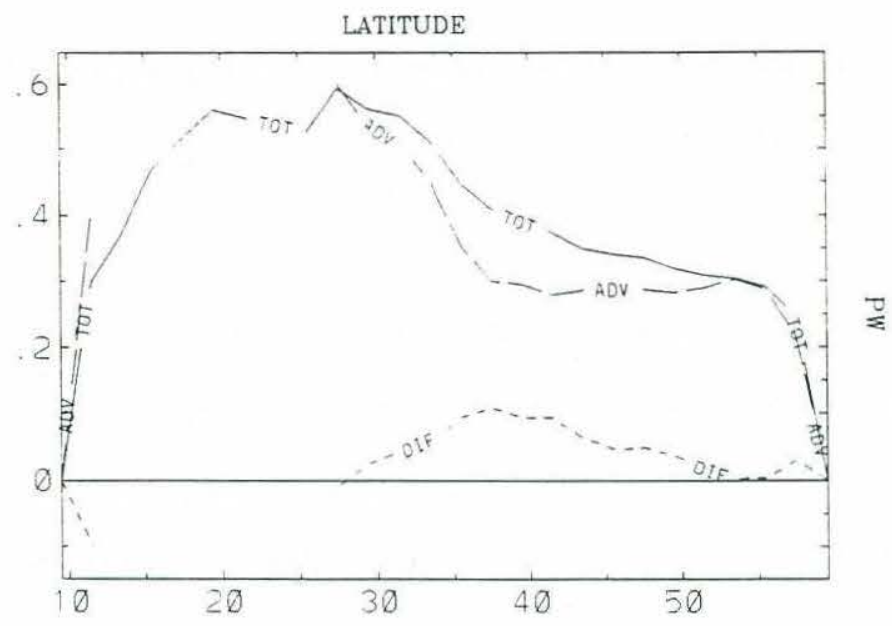

(b)

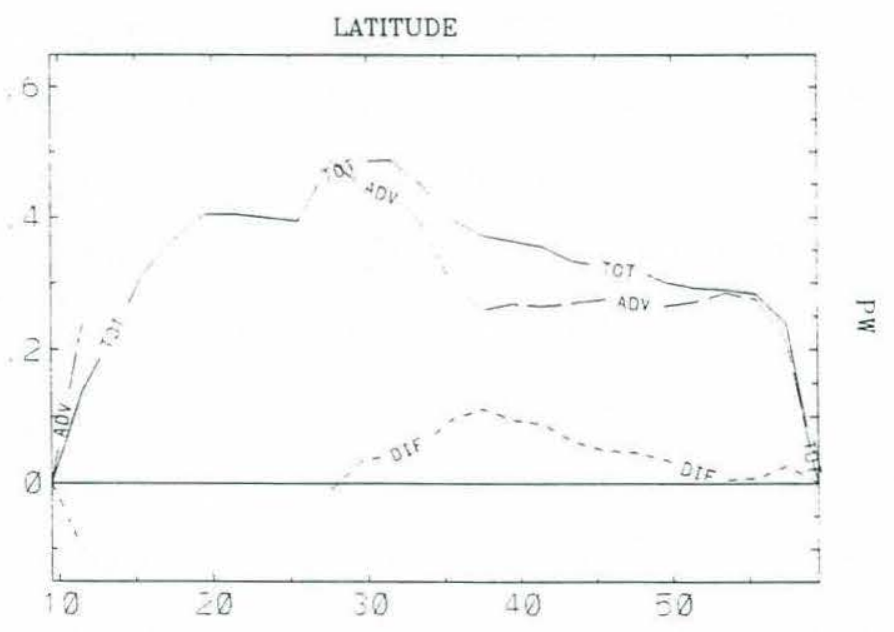

(c)

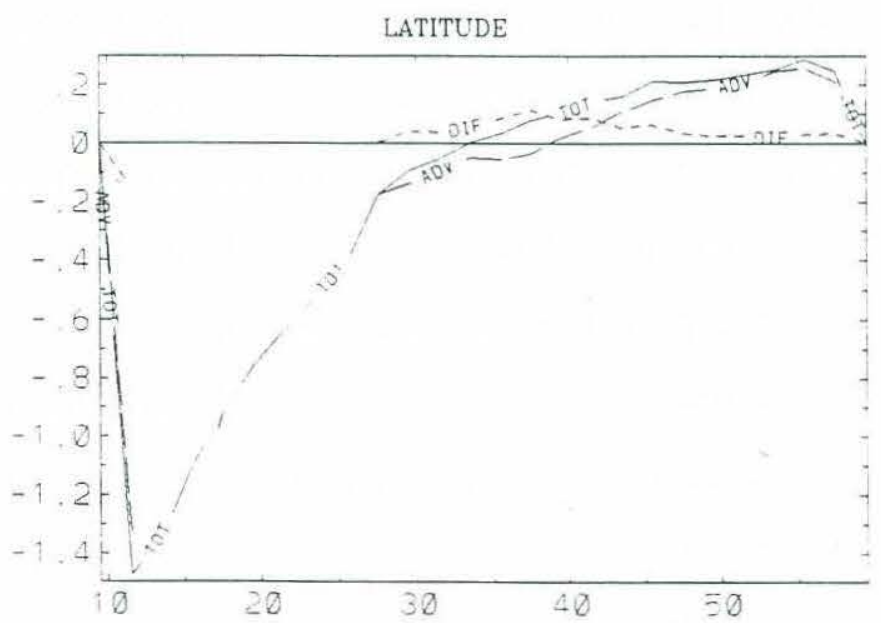

Figure 3.13: Zonally Averaged Heat Transport (PW) for (a) Run A, (b) Run 0, and (c) Run B 


\begin{tabular}{|c|c|c|c|c|c|}
\hline Run & $\begin{array}{c}\text { maximim } \\
\text { overturnizig } \\
\sim 55^{\circ} \mathrm{N}(\mathrm{Sv})\end{array}$ & $\begin{array}{l}\text { Uverturning } \\
\sim 25^{\circ} \mathrm{N}(\mathrm{Sv})\end{array}$ & $\begin{array}{c}\text { mean heat } \\
\text { transpori } \\
@ 27.5^{\circ} \mathrm{N}(\mathrm{PW})\end{array}$ & $\begin{array}{l}\text { flow leaving } \\
\text { S buundary } \\
(\mathrm{Sv})\end{array}$ & $\begin{array}{l}\text { "AABW" } \\
\text { entering } \\
(\mathrm{Sv})\end{array}$ \\
\hline-1 & 20 & 10 & 0.52 & 8 & 2 \\
\hline 0 & 17.0 & 7.9 & 0.50 & 5 & 1 \\
\hline A & 17.1 & 9.1 & 0.61 & 8 & 1 \\
\hline B & 18.4 & $\mathrm{n} / \mathrm{a}$ & -0.12 & $\mathrm{n} / \mathrm{a}$ & 23 \\
\hline $\mathrm{C}$ & 17.6 & 8.6 & 0.55 & 6 & 1 \\
\hline D & 18.4 & 11.1 & 0.60 & 9 & 1 \\
\hline
\end{tabular}

Table 3.2: Transports and Heat Fluxes of the Experiments. The row "Run -1 " contains the corresponding values of Experiment 1 of Marotzke and Wunsch (1993).

The hydrography, potential temperature and salinity, of the Runs C and D, through which we held $K_{V}=1 \mathrm{~cm}^{2} / \mathrm{s}$ fixed and reduced $K_{H}=5 \times 10^{6} \mathrm{~cm}^{2} / \mathrm{s}$ in Run C and $K_{H}=10^{6} \mathrm{~cm}^{2} / \mathrm{s}$ in Run D, are similar to the control run. Potential temperatures at the first model level are shown in Figures 3.14. The only trend worthy of note is that the isotherms and isohalines (not shown) acquire more fine strucure as one moves from the control run to the low diffusivity case. This is to be expected since the model needs some mechanism to dissipate unresolved structures, which is dependent upon the grid spacing, or resolution. As mentioned earlier, we are approaching the smallest diffusivity which accomplishes this for this model at this grid spacing, and therefore the increase of finer structure as the diffusivity is increased is to be expected.

Although the climatologies are similar within the series $0, C$, and $D$, the zonally averaged heat transport Figures 3.15 does increase slightly through the series 0, C, to D, though by not enough to be realistic (Hall and Bryden 1982, Isemer et al. 1989, and Trenberth and Solomon 1993). This difference indicates that the different $K_{H}$ values affect dynamical balances and hence (slightly) modify integral properties. Also, the eddy contributions to the transport decrease with decreasing $K_{H}$. The larger heat transports can be understood from the meridional mass transports shown in Figures 3.16. The maximum overturning strength increases slightly 
(a)

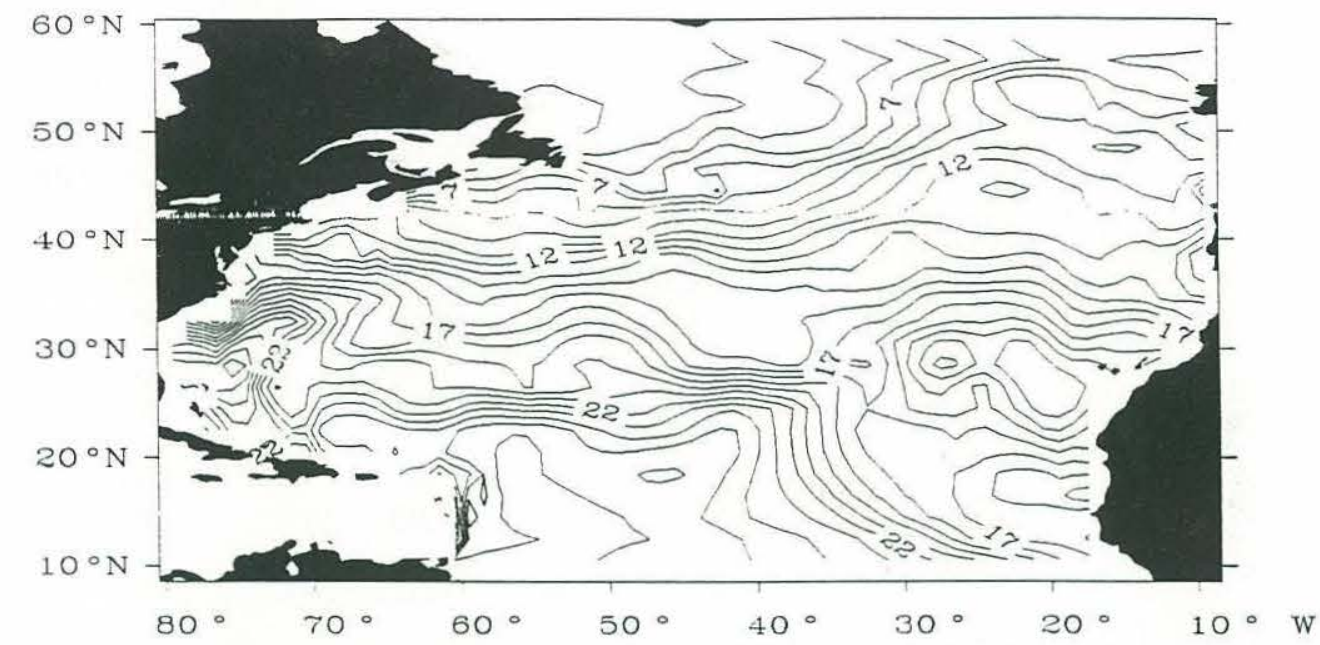

(b)

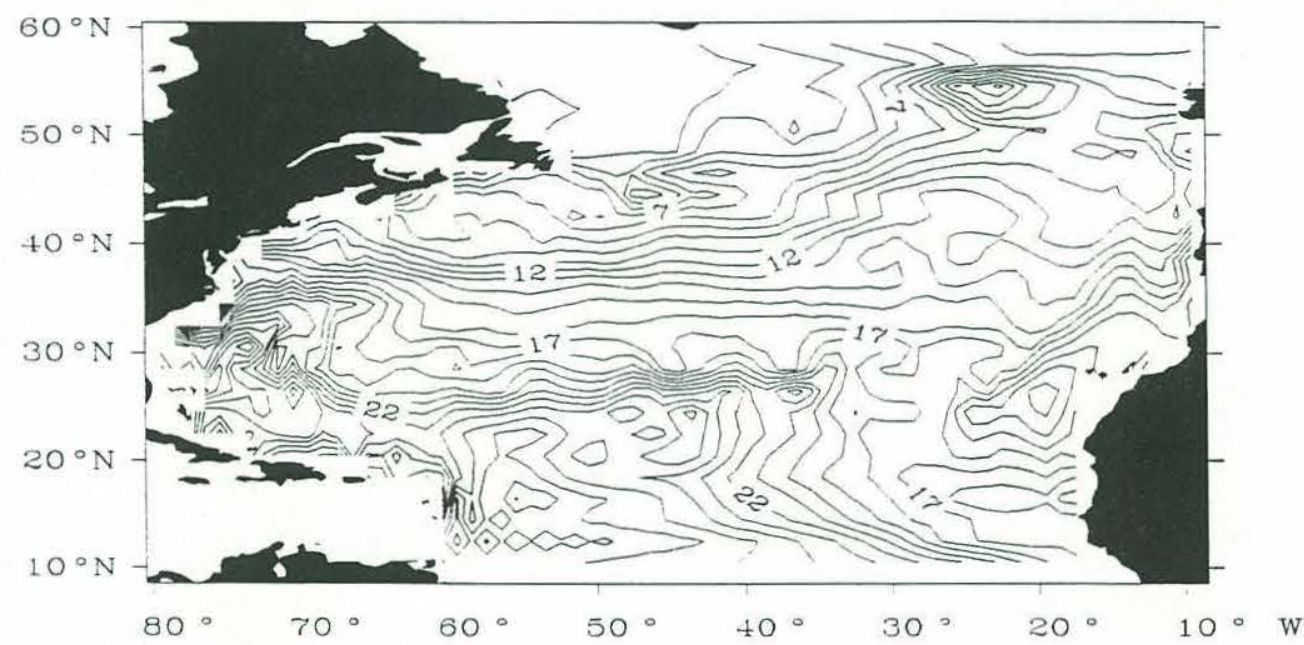

(c)

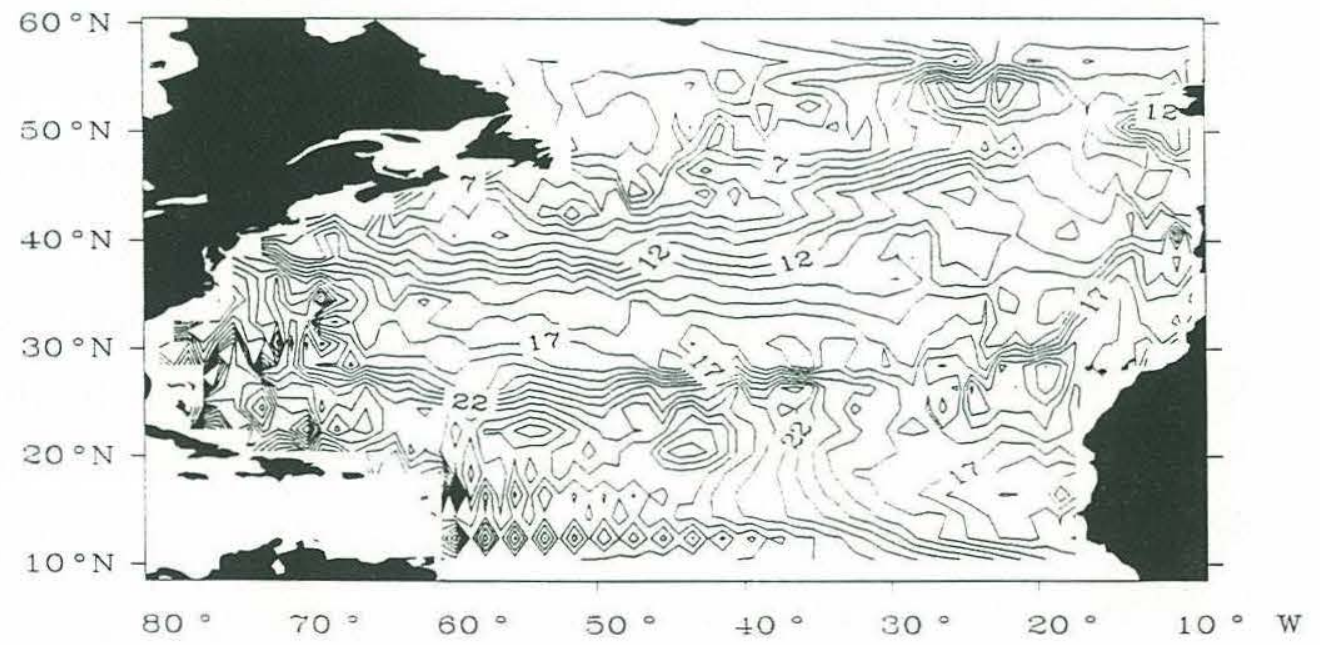

Figure 3.14: Potential Temperature at First Model Level for (a) Run 0 (repeated), (b) Run C, and (c) Run D. (interval $1^{\circ}$ ) 
(a)

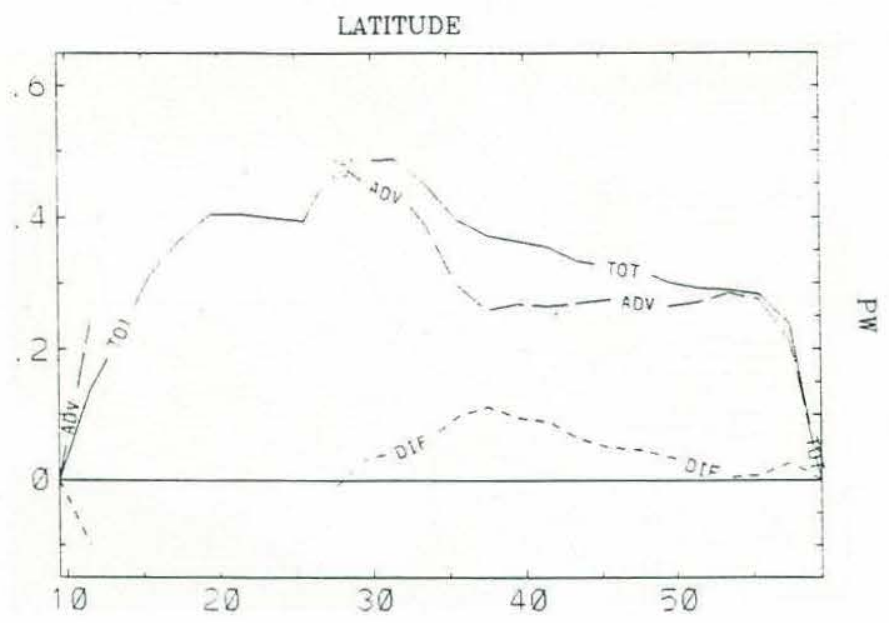

(b)

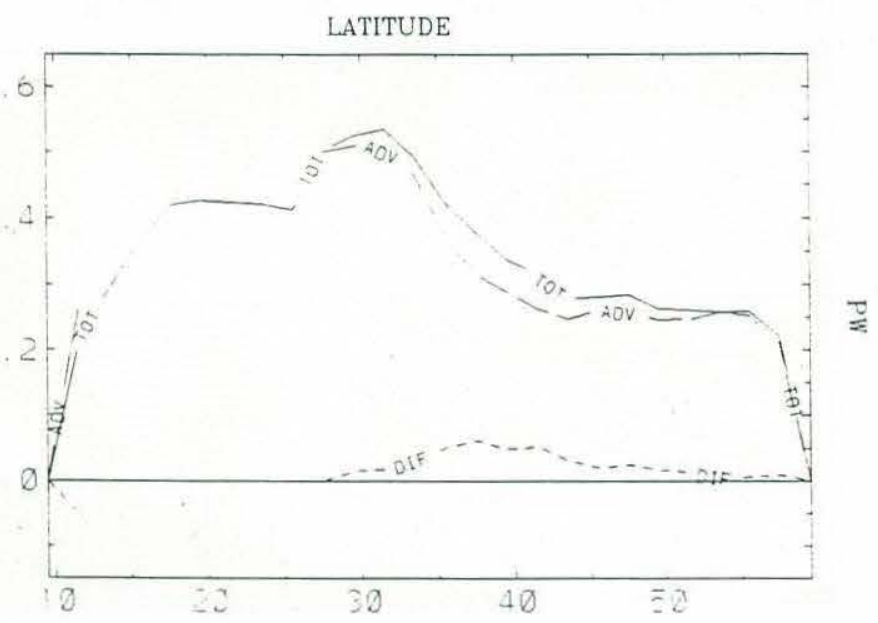

(c)

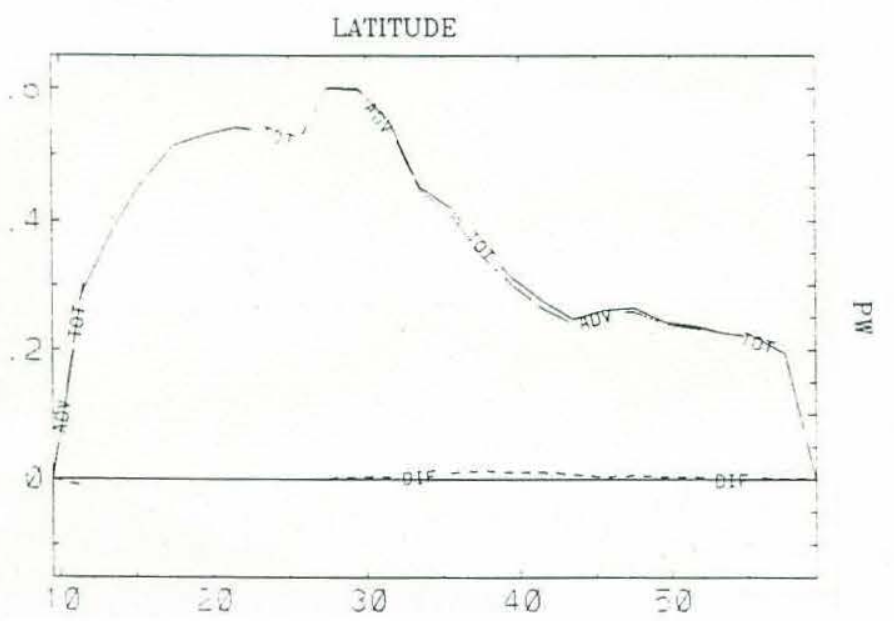

Figure 3.15: Heat Transports for (a) Run 0 (repeated), (b) Run C, and (c) Run D. 
(a)

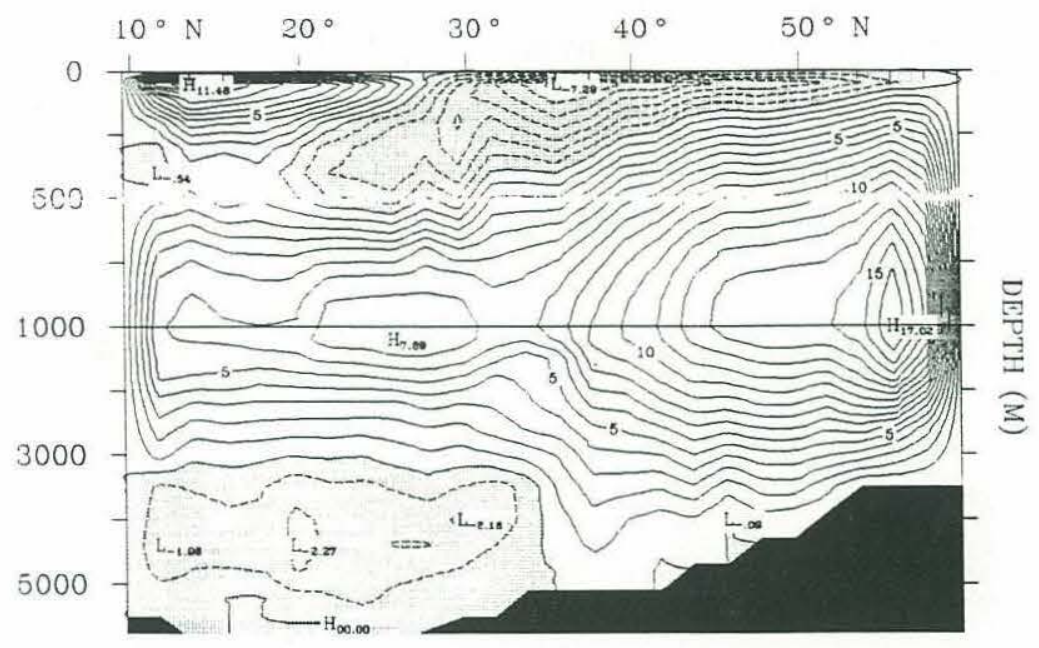

(b)

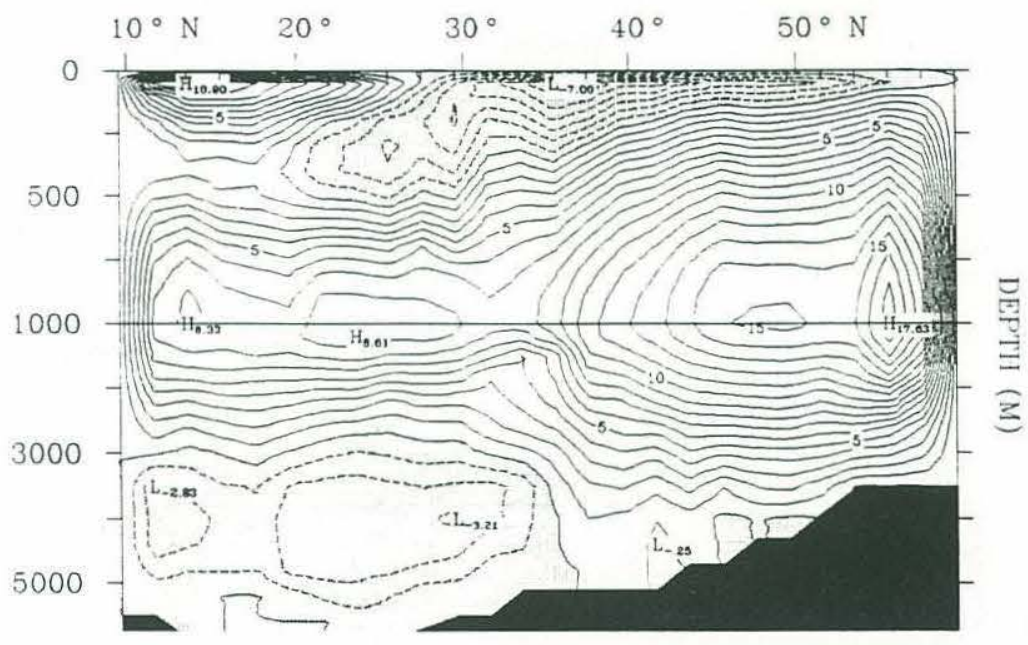

(c)

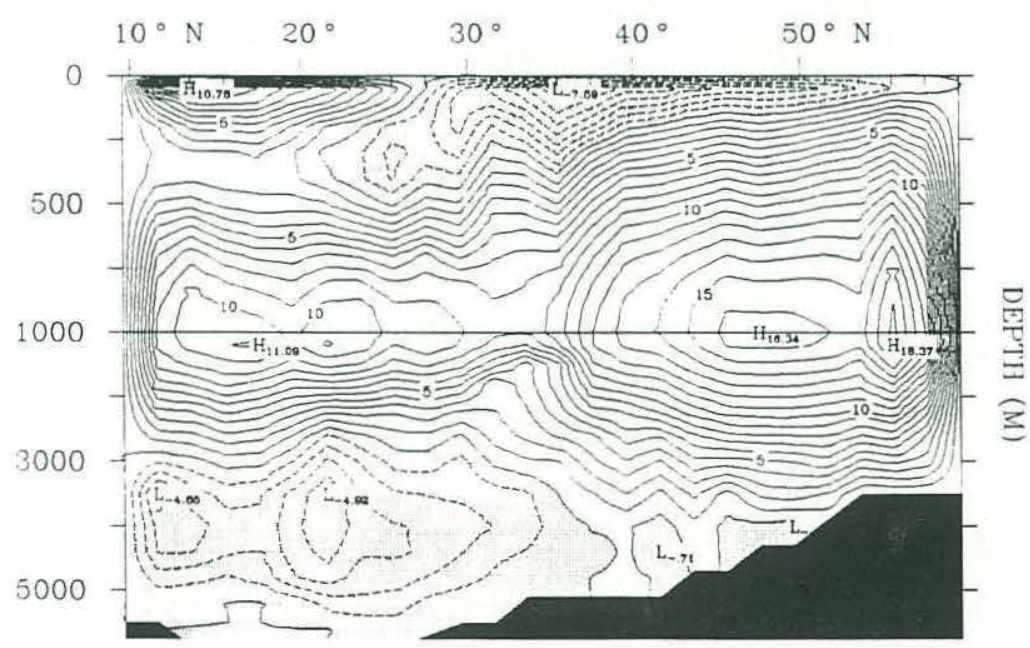

Figure 3.16: Meridional Mass Transports for (a) Run 0 (repeated), (b) Run C, and (c) Run D. (interval $1 \mathrm{~Sv}$, negative contours dashed, negative regions shaded.) 
from $17.0 \mathrm{~Sv}$ in Run 0, through 17.6 Sv in Run C, to $18.4 \mathrm{~Sv}$ in Run D, indicating more deep water formation at high latitudes, and the mid-latitude/mid-depth overturning maximum also increases from $7.9 \mathrm{~Sv}$, through $8.6 \mathrm{~Sv}$, to $11.1 \mathrm{~Sv}$ indicating more southward penetration of the cooler polar waters and less shortcutting through the mid-latitude upwelling highlighted by Böning et al. (1994). The two effects are strongest in Run D which, consequently, transports the most heat poleward of the series.

\subsection{Regional results}

We now turn our attention to the region of the spurious upwelling. We begin by examining the heat budget (Equations (2.2.1b) or (3.2.1)) of the control run in detail. We have just discussed integrated, and hence smoothed, properties of the circulation. We now focus on an unaveraged subregion of the model.

To discuss the heat budget in the subregion around Cape Hatteras, we need to quantify the magnitude of the time variation $\partial \theta / \partial t$ in Equation (3.2.1), since the model solution is not completely steady. The overall temporal drift extrapolated over 10 years is a measure of the steadiness of the optimized patterns over this time interval. Figure 3.17a shows the $\tau=10$ year extrapolated temporal drift of the potential temperature for the control run at a depth of $950 \mathrm{~m}$, a level at which the thermohaline shortcut ( $30 \sim 40^{\circ}$ Figure 3.13 and 3.15) should be pronounced. It appears to be an overall positive pattern, indicating the presence of some unresolved structures in this residual for which the optimization has not accounted. However our point here is to notice that the extrapolated temporal drift is in the range -2.5 to $2.5^{\circ} \mathrm{C}$. The corresponding heat budget $\Delta \theta / \Delta t$ evaluated for $\Delta t=12$ hours, shown in Figure 3.17b, is generally $\mathcal{O}\left(10^{-8}\right)^{\circ} /$ sec. Since 10 years $\sim \mathcal{O}\left(3 \times 10^{8}\right)$ sec, we see that the two measures of steadiness are quite consistent. It is also important to notice that the heat budget in the region Figure $3.17 \mathrm{~b}$ is basically steady, except for a strong dipole feature in the lower right of the frame. In Figure 3.18, the vertical advection 
(a)

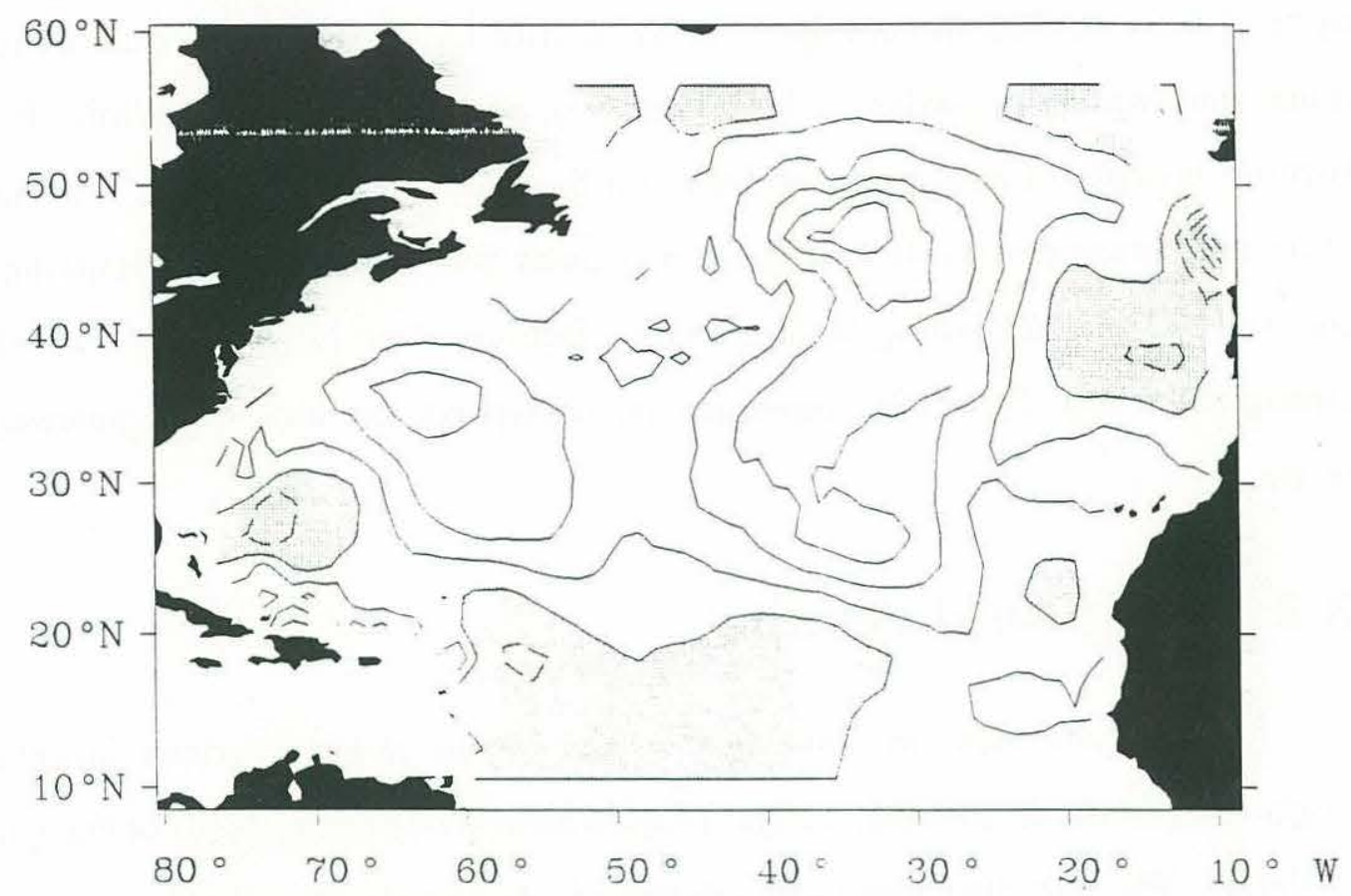

(b)

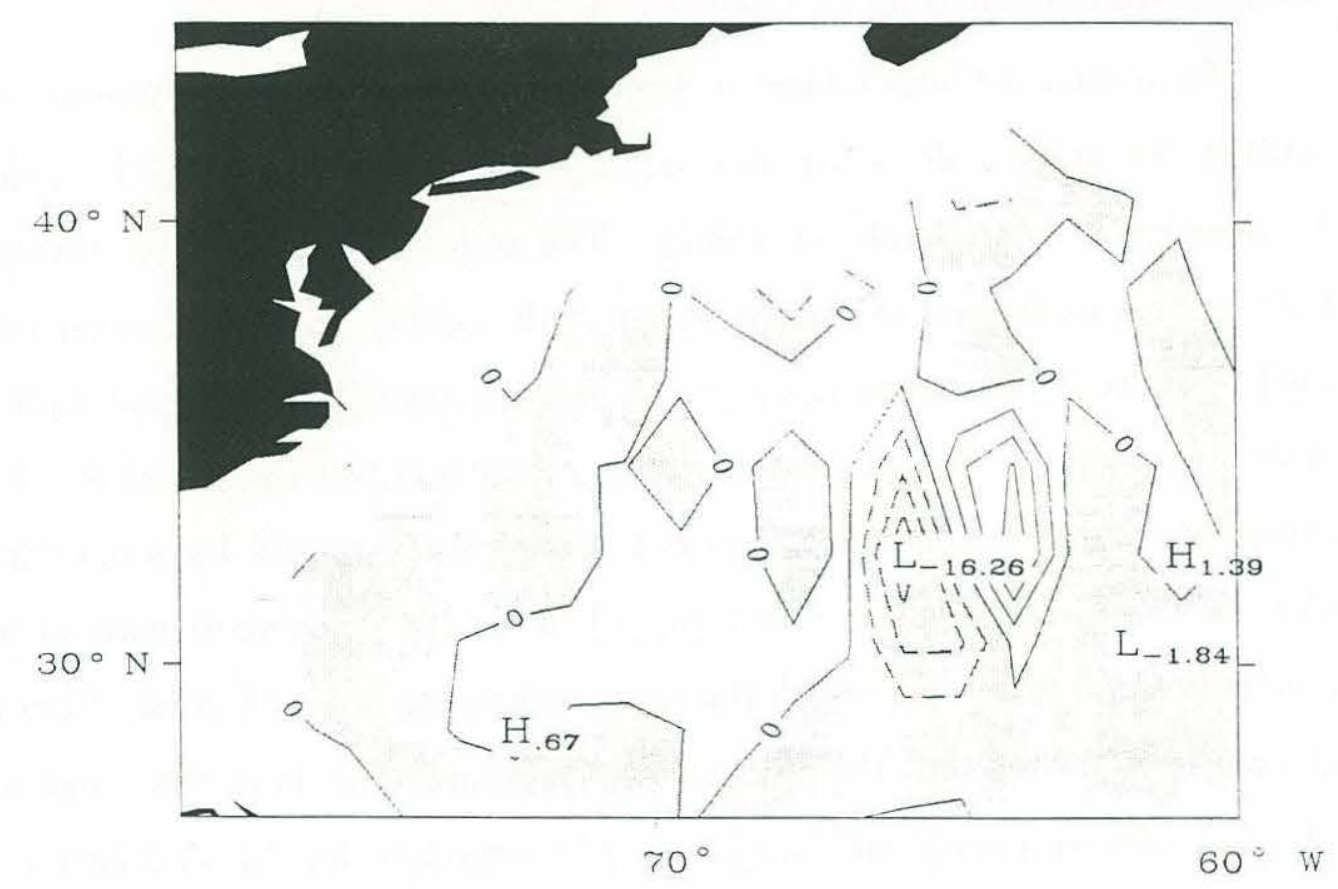

Figure 3.17: Measures of Steadiness for Run 0 at $950 \mathrm{~m}$ Depth. (a) $\tau=10$ year extrapolated temporal drift of $\theta$ for entire basin (interval 0.5), (b) $\Delta \theta / \Delta t$ for the subregion of the spurious upwelling (scaled by $10^{8}$, interval 4 ). 


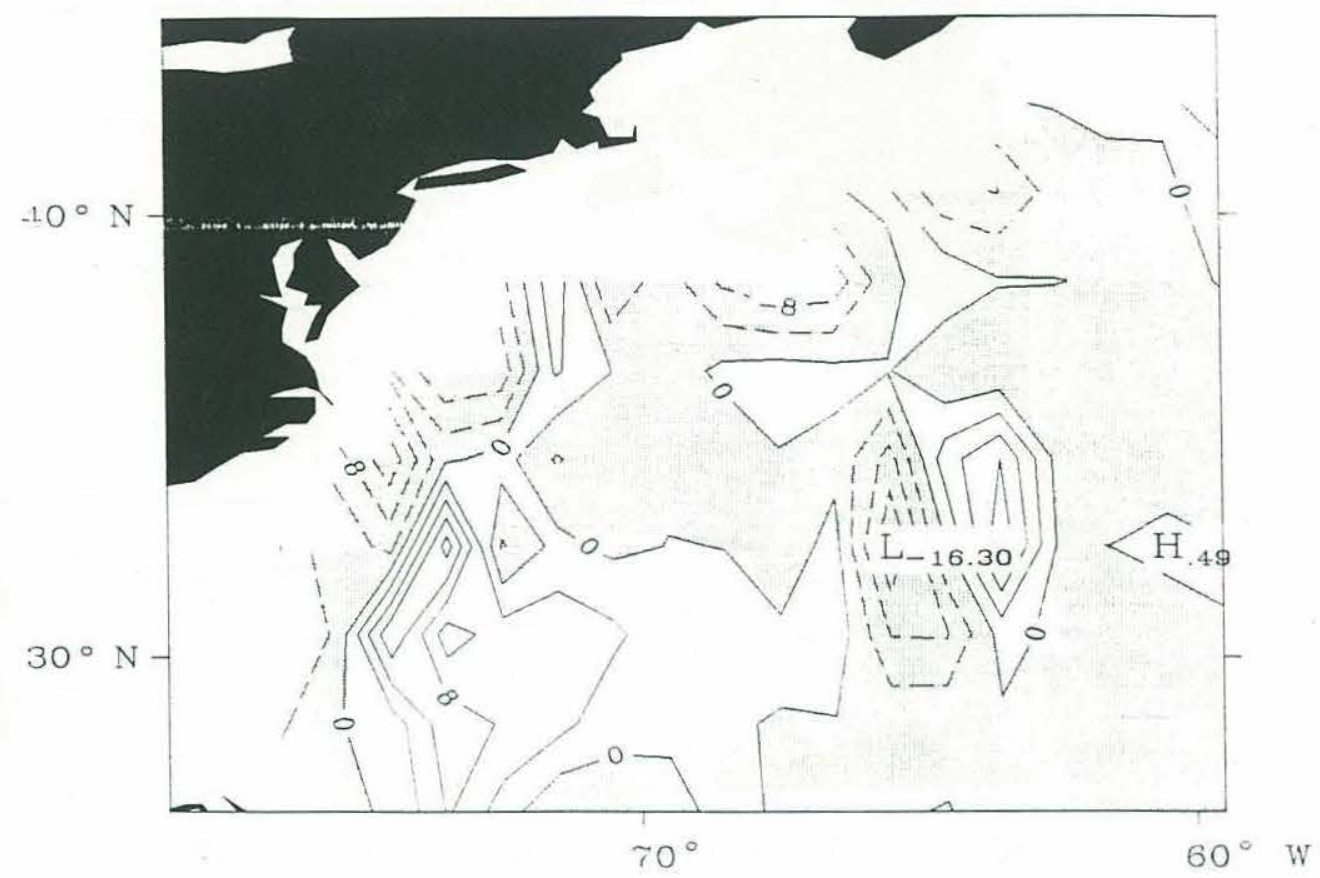

Figure 3.18: Vertical Advection in the Subregion. (Scaled by $10^{8}$, interval 0.4 )

of potential temperature, we see the same dipole feature. It is the manifestation of Bermuda and is a consequence of the JEBAR effect and the incompatibility between the rough topography and the smooth Levitus climatology. Vertical heat advection is not limited to this structure. Figure 3.18 shows extended regions of both heating and cooling along the ocean boundary. These features, absent in the overall budget Figure $3.17 \mathrm{~b}$, must be balanced by other terms.

Briefly, Figure 3.19, the potential temperature at this depth, shows fairly even-tempered mid-latitude water mostly between 6 to $7^{\circ} \mathrm{C}$. Diffusion of heat, governed by a second derivative, occurs where the temperature surface has the most curvature. Aside from a small region within the northern sponge layers towards Iceland, the potential temperature surface is most curved in the subregion of interest, where the isotherms turn from zonal to meridional. There, the curvature is mostly negative, suggesting diffusive zonal cooling.

Indeed Figures 3.20, showing both horizontal diffusion terms, display these characteristics. Away from the western boundary, where the potential temperature surface Figure 3.19 is smooth, the horizontal diffusion terms practically vanish. In 


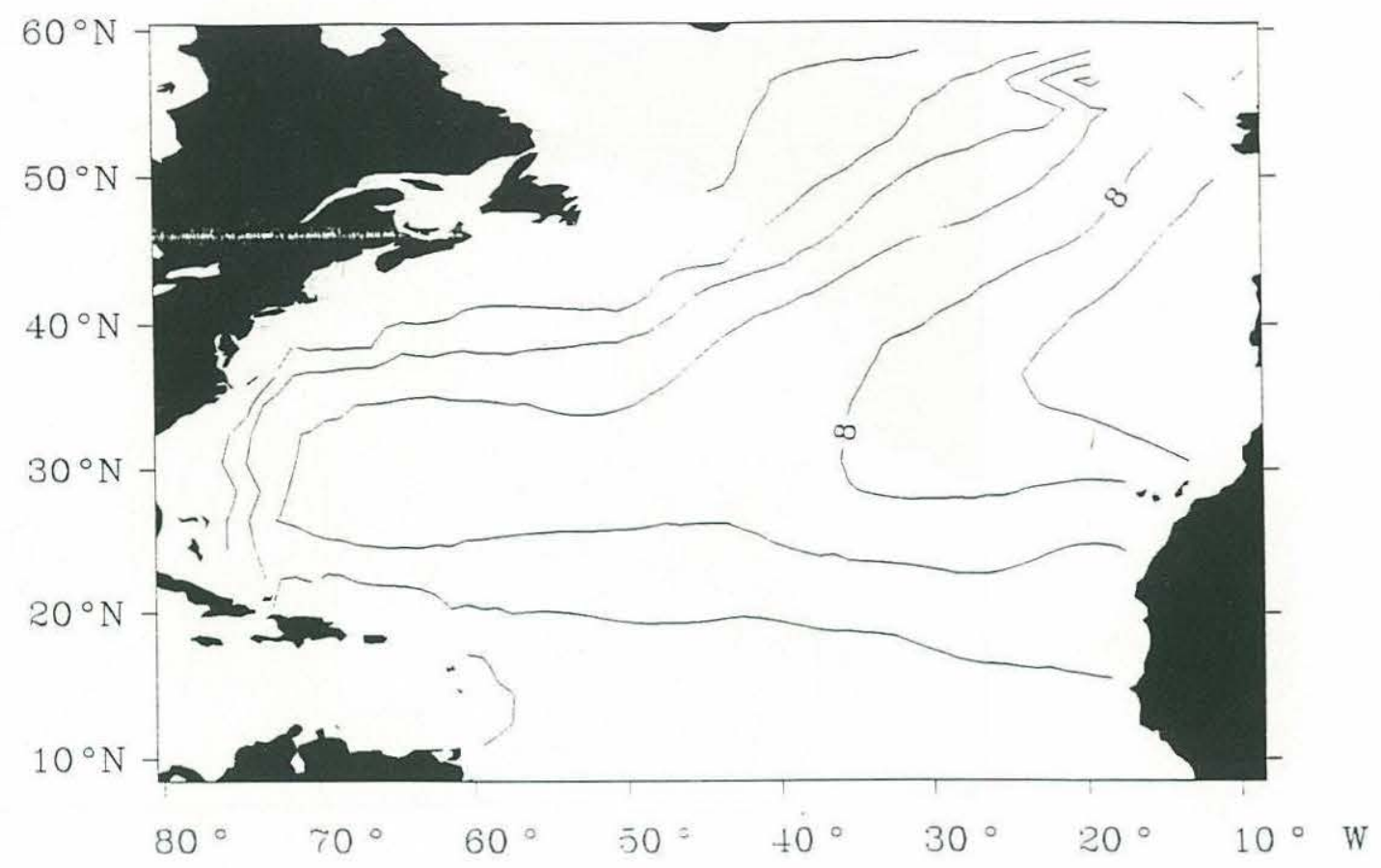

Figure 3.19: Potential Temperature at $950 \mathrm{~m}$ Depth. (interval $1^{\circ}$ )

particular, the strong dipole structure observed in the heat budget (Figure 3.17b) due to vertical advection (Figure 3.18 ) is completely absent. Also, note that the meridional heat diffusion (Figure $3.20 \mathrm{~b}$ ) is an order of magnitude smaller than the zonal (Figure 3.20a), and that the zonal term does generally exhibit cooling, except at the western most edge of the region where warming slight occurs.

To examine whether the the vertical advection and horizontal diffusion balance, we combine them. Their sum is shown in Figure 3.21. Instead of nearly cancelling in the regions away from the previously discussed interior dipole, the sum of the terms which were supposed to balance has introduced a second dipole. The discrepancy cannot be met by the vertical diffusion, shown in Figure 3.22, which not only is two orders of magnitude smaller, but exhibits no dipoles.

The two remaining terms in the heat budget, the horizontal advection terms, are shown in Figure 3.23. The meridional advection term, Figure 3.23b, exhibits a monopolar structure only while the zonal advection term exhibits a dipole structure in roughly the same boundary region as the two-term sum, Figure 3.21, with the opposite polarity. However, instead of approximating the heat budget, the three-term 
(a)

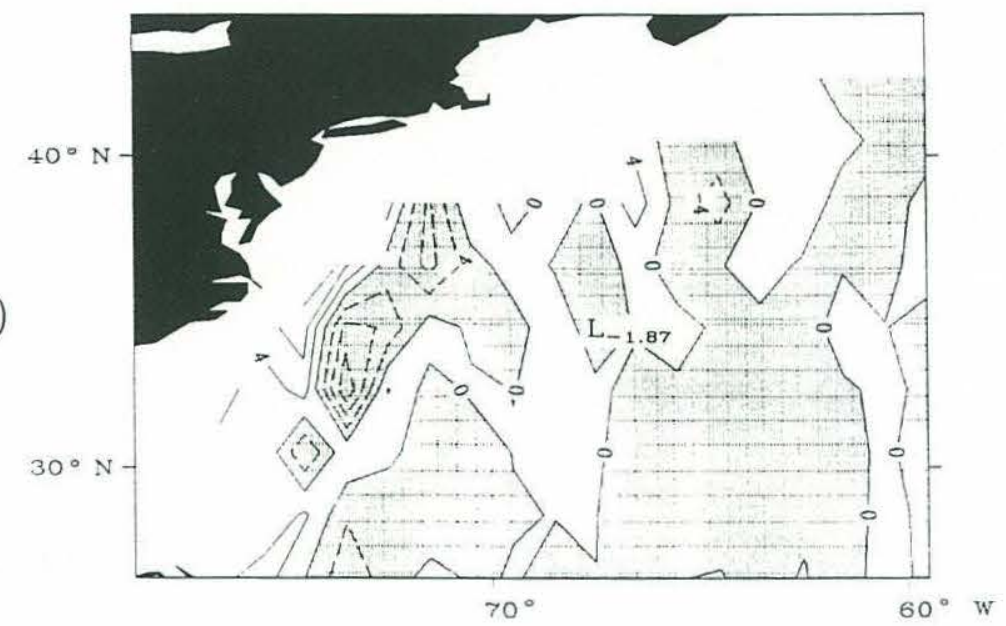

(b)

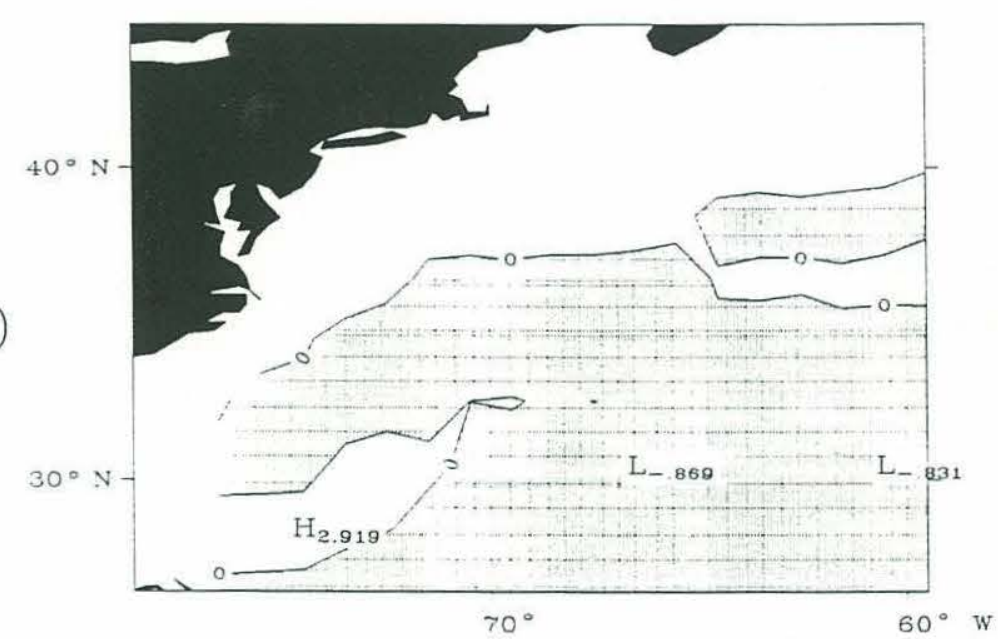

Figure 3.20: Horizontal Diffusion Terms. (a) Zonal Diffusion and (b) Meridional Diffusion (scaled by $10^{8}$, interval 4 


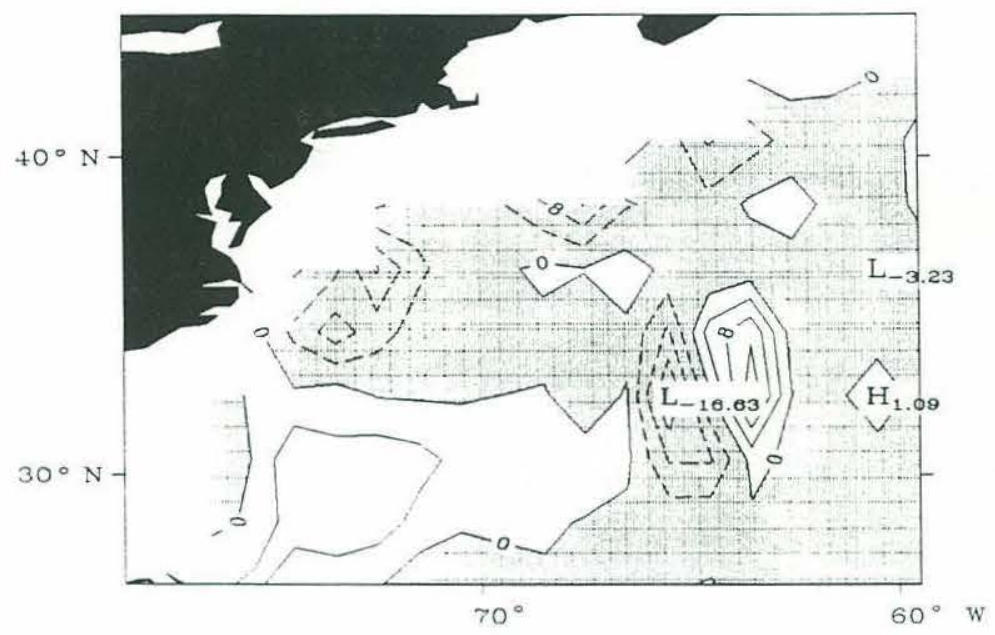

Figure 3.21: Two Terms in the Heat Budget: $K_{H} T x x-w T_{z}$. (Scaled by $10^{8}$, interval 4)

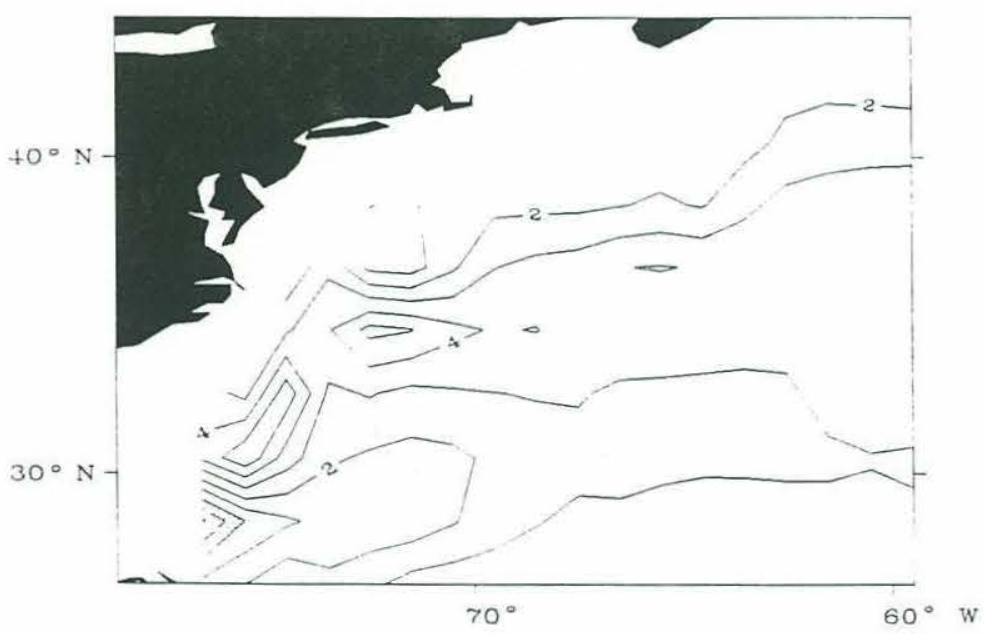

Figure 3.22: Vertical Diffusion $K_{V} T_{z z}$. (Scaled by $10^{9}$, interval 1) 
(a)

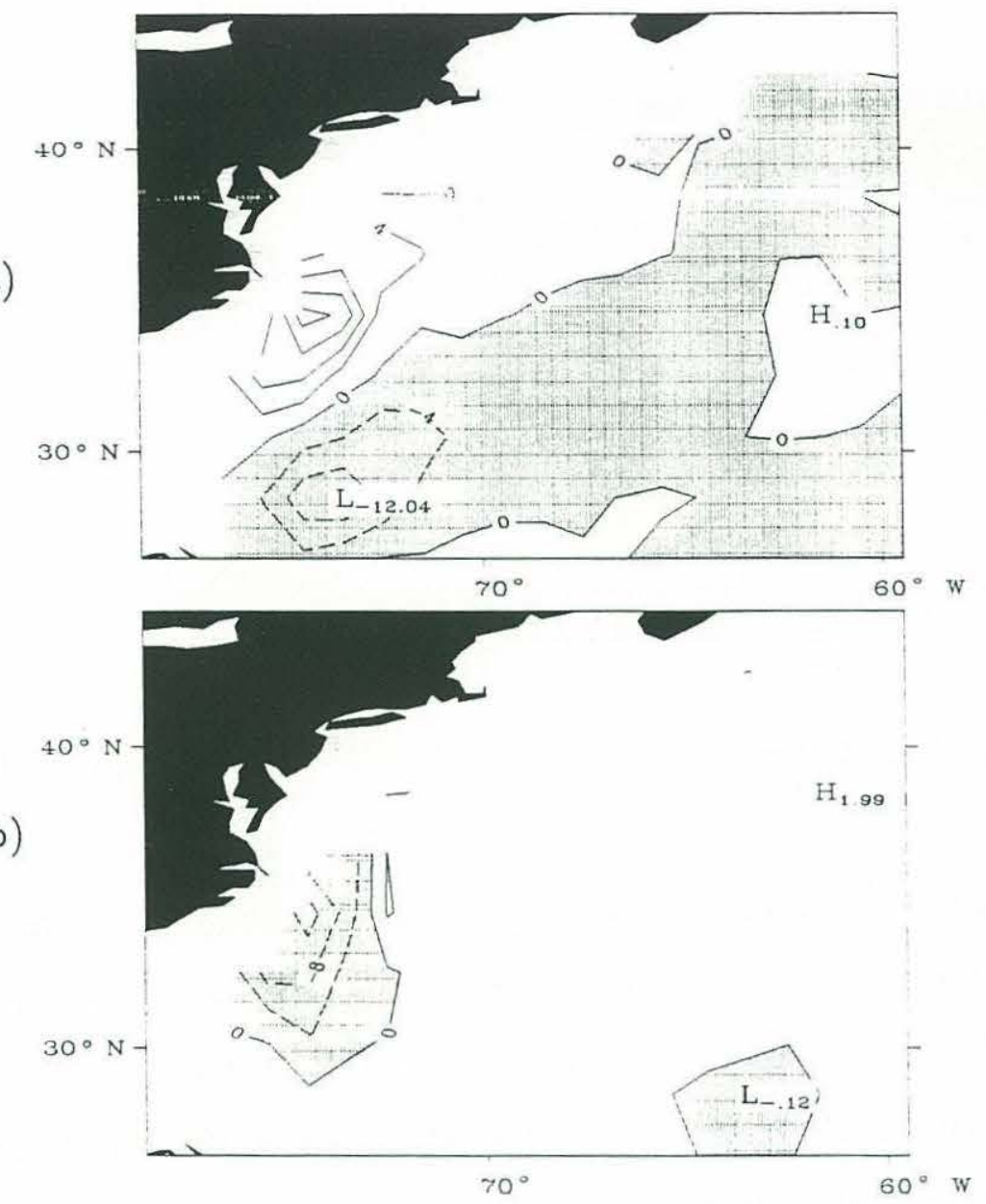

Figure 3.23: Horizontal Temperature Advection Terms (a) zonal advection (b) meridional advection. (scaled by $10^{8}$, interval 4 )

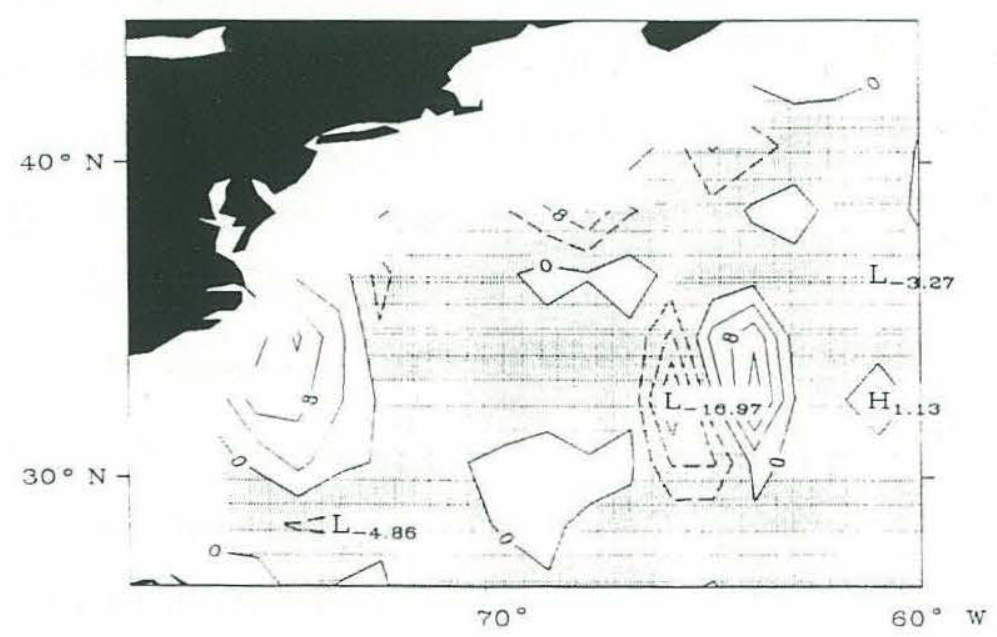

Figure 3.24: Three Terms of the Heat Budget: $K_{H} T_{x x}-w T_{z}-u T_{x}$. (Scaled by $10^{8}$, interval 4) 


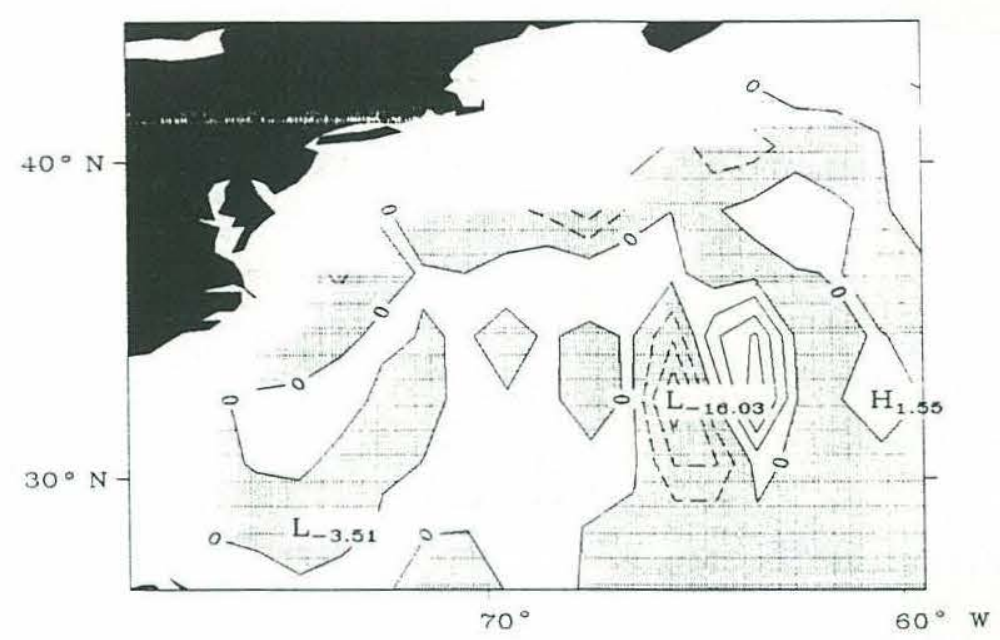

Figure 3.25: Four Terms of the Heat Budget: $K_{H} T_{x x}-u T_{x}-v T_{y}-w T_{z}$. (Scaled by $10^{8}$, interval 4)

sum (Figure 3.24) formed by adding the zonal advection to the balance previously examined (Figure 3.21), resembles the meridional advection with the opposite polarity in the boundary region. Indeed only when all three advective terms are combined with the zonal diffusion, Figure 3.25, is the heat budget of Figure 3.17b fully recovered. Therefore, as in the other experiments which were substantially similar, the balance observed here is a four-term balance and not a two-term balance.

We now examine the vertical velocity itself. The vertical velocity, $w$, of the control run, Figure 3.26b, shows upwelling over an extended region with large maximum upwelling velocities on the order of $3 \times 10^{-3} \mathrm{~cm} / \mathrm{s}$, as in Böning et al. (1994). In Runs $\mathrm{A}$ and $\mathrm{B}$, Figures 3.26a and $\mathrm{c}$, with the same horizontal eddy diffusivity $K_{H}=10^{7} \mathrm{~cm}^{2} / \mathrm{s}$, the spurious upwelling occurs over a broad region inshore of the Gulf Stream path with roughly the same magnitude as the control. The extent of the upwelling is greatly reduced as one reduces the horizontal eddy diffusivity from $K_{H}=5 \times 10^{6} \mathrm{~cm}^{2} / \mathrm{s}$ in Run C, Figure 3.27a down to $K_{H}=10^{6} \mathrm{~cm}^{2} / \mathrm{s}$ in Run D, Figure 3.27b. The magnitude of the upwelling hardly changes in Run C, with a maximum of about $5 \times 10^{-3} \mathrm{~cm} / \mathrm{s}$, but almost triples to $8 \times 10^{-3} \mathrm{~cm} / \mathrm{s}$ at one center in Run D. However, the upwelling centers in Run D, Figure $3.27 \mathrm{~b}$, are very small while 
(a)

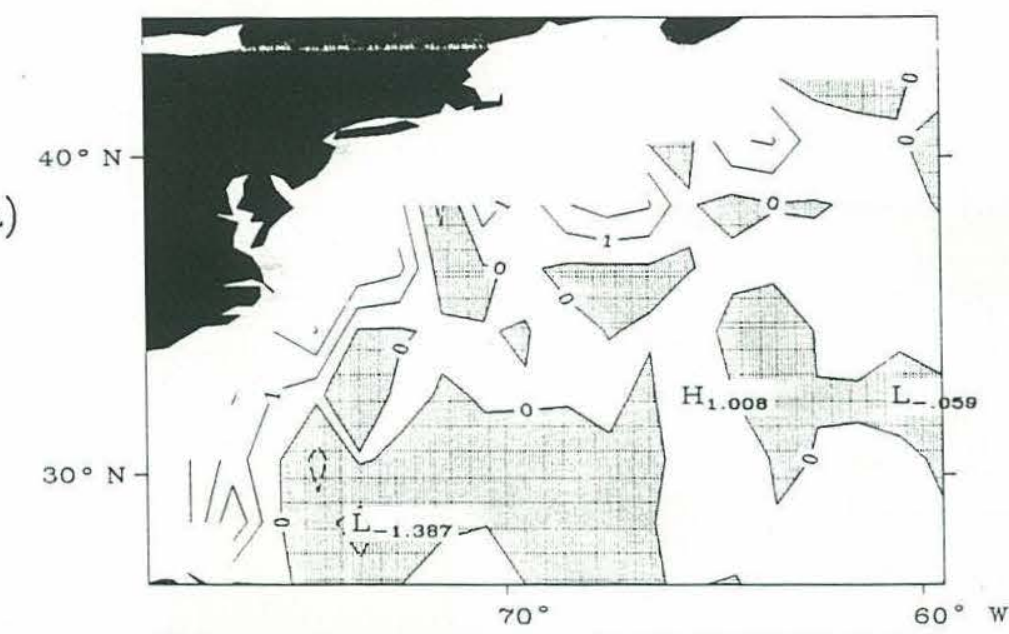

(b)

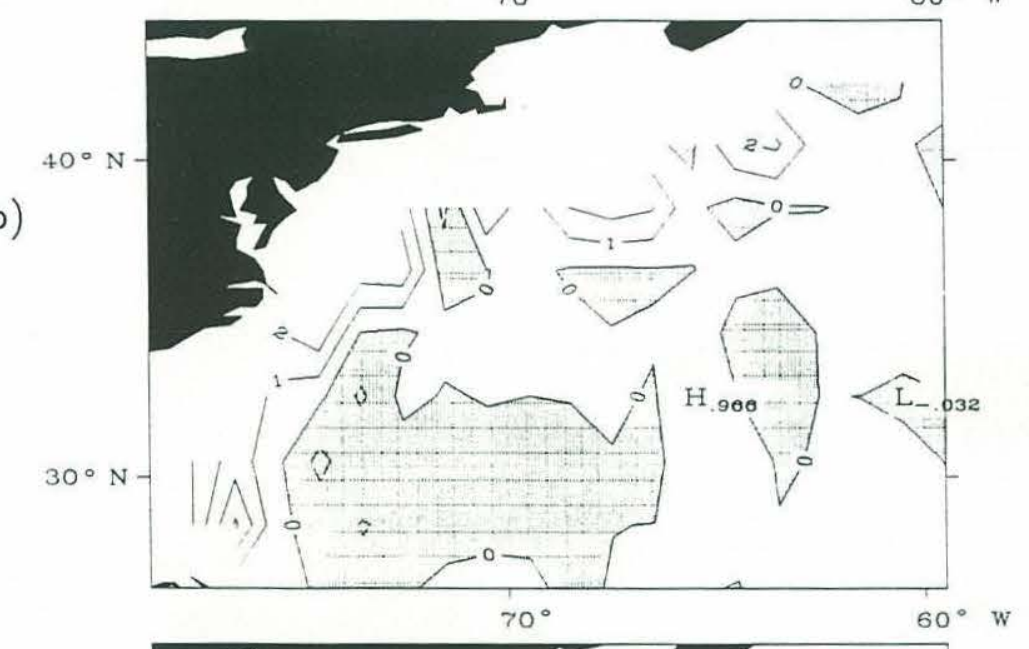

(c)

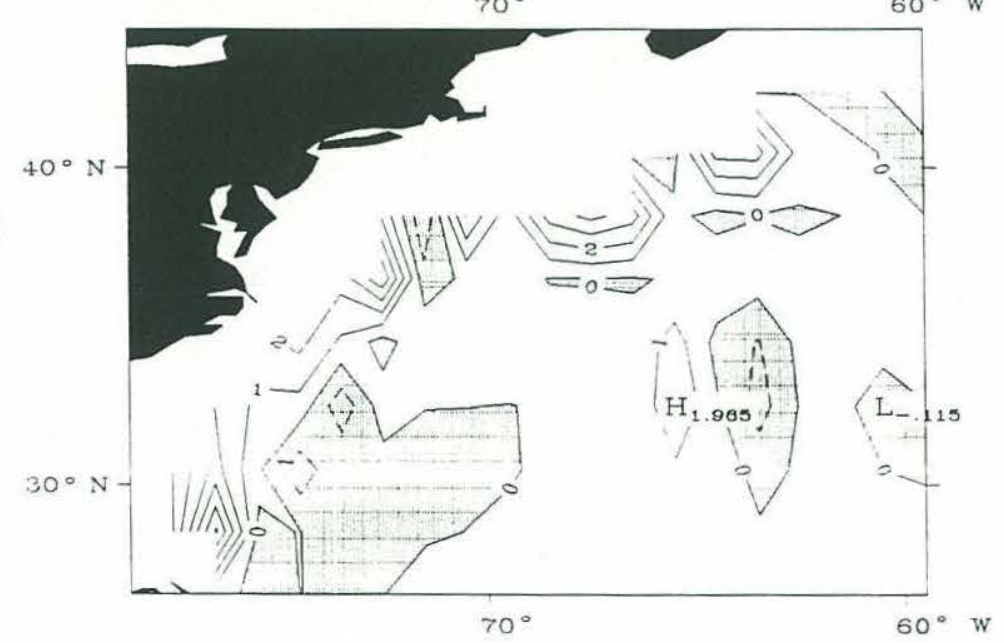

Figure 3.26: Vertical Velocity $w$ for (a) Run A, (b) Run 0, (c) Run B. (scaled by 1000, interval 1) 
(a)

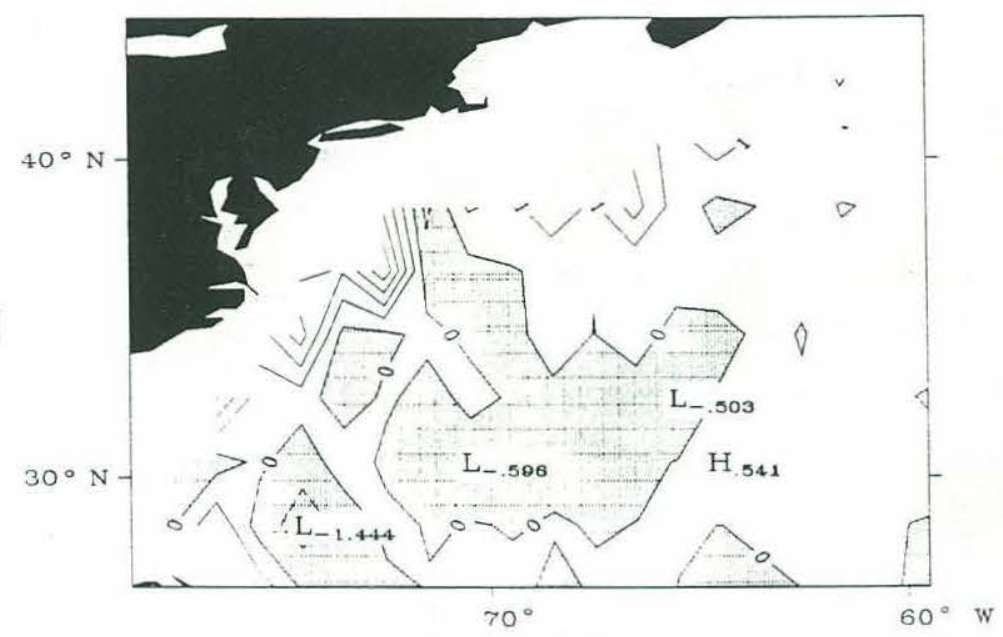

(b)

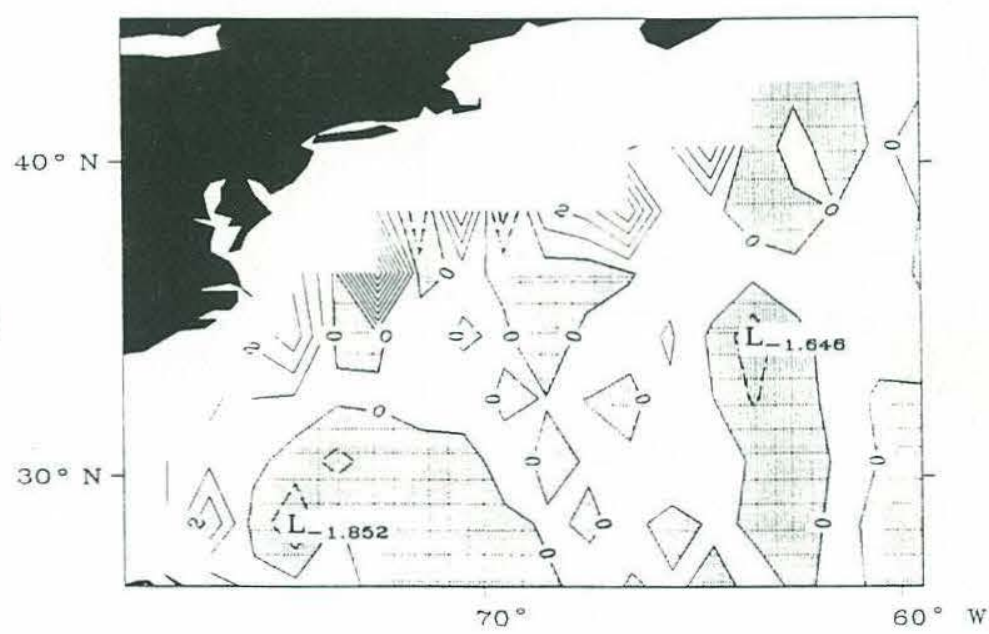

Figure 3.27: Vertical Velocities of (a) Run C, (b) Run D. (scaled by 1000, interval 1) 
in Runs A and B, Figures 3.26a and c, the spurious upwelling occurs all over and along the continental shelf, as well as in the control run. Thus, from these Figures, it appears that reducing the horizontal eddy diffusivity does lead to a reduction in magnitude of the overall upwelling slopeward of the Gulf Stream which decreases the thermohaline shortcut and consequently allows a larger northward heat transport in Runs C and D. To further facilitate comparison between runs, the vertical transport across the region of interest could be calculated and the resulting integral scalar measure should more concisely reflect the differences between the runs. In any case, the overall balance is not as clear-cut as Veronis (1975) and Böning et al. (1994) suggest. 


\section{Chapter 4}

\section{Conclusions}

As far as the "goodness" of these inverse calculations is concerned, we note that a minimum was indeed found for each of the experiments, as examination of the different components of the different cost functions shows (Table 3.1). However, the large 10 year extrapolated temporal drift of the control (and other) experiments shows that we are in the same situation as Experiment 3 of Marotzke and Wunsch (1993), viz. the steady state is not simulaneously consistent with both the Levitus climatology and the climatology of surface fluxes.

Aside from the parameter choice $K_{V}=10 \mathrm{~cm}^{2} / \mathrm{sec}$ of Run B which is rather beyond the range of acceptable values and produced circulation features extremely different from those observed in the real ocean, the optimal circulations produced in this suite of experiments are remarkably similar. Data assimilation via the adjoint is insensitive to the choice of eddy diffusivity coefficients $\left(K_{H}, K_{V}\right)$. Bryan (1987) performed a sensitivity study of the GFDL model (with full momentum equations, $4.5^{\circ} \times 3.75^{\circ}$ meridional $\times$ zonal horizontal resolution and 12 vertical levels) to specification of vertical eddy diffusivity $K_{V}$ and noticed that the model was extremely sensitive to that parameter. In a suite of experiments with vertical eddy diffusivity $K_{V}$ ranging from 0.1 to $5 \mathrm{~cm}^{2} / \mathrm{sec}$ (within the range we studied) he observed the

maximum strength of the mean meridional overturning cell increase exponentially (third power roughly) as a function of $K_{V}$ from about $9 \mathrm{~Sv}$ when $K_{V}=0.1 \mathrm{~cm}^{2} / \mathrm{sec}$, 
through about $18 \mathrm{~Sv}$ when $K_{V}=1.0 \mathrm{~cm}^{2} / \mathrm{sec}$ to about $40 \mathrm{~Sv}$ when $K_{V}=5.0 \mathrm{~cm}^{2} / \mathrm{sec}$, a totally unrealistic result indicating that even $K_{V}=5.0 \mathrm{~cm}^{2} / \mathrm{sec}$ is not within the acceptable range. The heat transports of his series showed similar, though not exponential, sensitivity, with the heat transport of the experiment with $K_{V}=2.5 \mathrm{~cm}^{2} / \mathrm{sec}$ being roughly twice that of the $K_{v}=1.0 \mathrm{~cm}^{2} / \mathrm{sec}$ experiment, whose heat transport itself was roughly four times larger than that of the $K_{V}=0.1 \mathrm{~cm}^{2} / \mathrm{sec}$ experiment. Instead, in the suite of data assimilation experiments performed here, the maximum mean meridional overturning varies from 17.0 to $18.4 \mathrm{~Sv}$ (Table 3.2) and the maximum heat transports fall in the range of 0.5 to $0.6 \mathrm{Pw}$ (Figures 3.13 and 3.15 , except for Run B) throughout the parameter range. Although the overturning strengths do change between experiments and the heat transports do shift in the expected directions as the eddy diffusivities are varied, the changes observed here in this data assimilation study are incremental and nowhere near the magnitudes observed in Bryan's (1987) PE study.

The fact that the optimal circulation estimated by the adjoint is so robust under vertical diffusivity changes suggests that it is giving us the circulation consistent with our specified winter climatology of Levitus (1982). In particular the heat transport of $0.6 \mathrm{Pw}$, or so, around $25^{\circ} \mathrm{N}$ is what is consistent with this winter climatology.

Thus in answer to the questions posed in the introduction, we conclude:

1. The inverse calculations, in contrast to the purely prognostic ones, are rather insensitive to the choice of $\left(K_{H}, K_{V}\right)$ except for the unrealistic Run B. This insensitivity is manifested in the almost invariant values found in all the experiments for the NADW production rate and meridional heat transports at $27^{\circ} \mathrm{N}$ ( 0.6) $\mathrm{PW}$ as discussed above. This insensitivity shows that the optimization procedure corrects for the sensitivity of the prognostic model as the estimates of the above quantities are kept consistent with the observations. Thus overestimates/underestimates of integral properties (such as the underestimated 
meridional heat tansport) reflect not the model sensitivity to the parameter values but the dependencies of the observational dataset used.

2. We always find upwelling in the region inshore of the Gulf Stream. However, we are able to reduce the sizes of the upwelling region by reducing the horizontal diffusivity $K_{H}$. Moreover in contrast to the prognostic calculations of Böning, et al. (1994), the balance in the upwelling region is not simply the Veronis balance of vertical upwelling versus horizontal tracer diffusion. Now a three-component balance is involved, with horizontal heat difusion, vertical heat upwelling, and horizontal heat advection all of the same magnitude. This three-component balance, in contrast to the two-term balance noted by Veronis in the prognostic model, must be introduced by the required consistency with Levitus climatology imposed by the adjoint calculations. The dynamical reasons for this difference are however not straightforward. 


\section{References}

Böning, C.W., F.O. Bryan, and W.R. Holland, 1993: Modeling the subpolar North Atlantic, in The North Atlantic Current System: A Scientific Report, MalanotteRizzoli and Rossby, eds., WHOI, 53-64.

Böning, C.W., W.R. Holland, F.O. Bryan, G. Danabasoglu, and J.C. McWilliams, 1994: An overlooked problem in model simulations of the thermohaline circulation and heat transport in the Atlantic Ocean. J. Clim., submitted.

Bryan, F., 1987: Parameter sensitivity of primitive equation ocean general circulation models. J. Phys. Oceanogr., 17, 970-985.

Bryan, K., 1969: A numerical method for the study of the circulation of the world ocean. J. Comput. Phys., 4, 347-376.

Cox, M., 1984: A primitive equation, three-dimensional model of the ocean. GFDL Ocean Group Tech. Rep. No. 1, Geophysical Fluid Dynamics Laboratory, Princeton University.

Gent, P.R. and J.C. McWilliams, 1990: Isopycnal mixing in ocean circulation models. J. Phys. Oceanogr., 20, 150-155.

Hall, M.M. and H.L. Bryden, 1982: Direct estimates and mechanisms of ocean heat transport. Deep Sea Res., 29, 339-359.

Hellerman, S. and M. Rosenstein, 1983: Normal monthly wind stress over the world ocean with error estimates. J. Phys. Oceanogr., 13, 1093-1104.

Holland, W.R., 1971: Ocean tracer distributions-a preliminary numerical experiment. Tellus, 23, 371-392.

Holland, W.R., 1978: The role of mesoscale eddies in the general circulation of the ocean-numerical experiments using a wind-driven quasi-geostrophic model. $J$. Phys. Oceanogr., 8, 363-392.

Holland, W.R., and F.O. Bryan, 1994a: Modelling the wind and thermohaline circulation in the North Atlantic Ocean, in Ocean Processes in Climate Dynamics: Global and Mediterranean Examples, Malanotte-Rizzoli and Robinson, eds. Kluwer Academic, 135-156.

Holland, W.R., and F.O. Bryan, 1994b: Sensitivity Studies on the Role of the Ocean in Climate Change, in Ocean Processes in Climate Dynamics: Global and Mediterranean Examples, Malanotte-Rizzoli and Robinson, eds. Kluwer Academic, 111-134. 
Isemer, H.J., J. Willebrand, and L. Hasse, 1989: Fine Adjustment of Large Scale AirSea Energy Flux Parametrization by a Direct Estimate of Ocean Heat Transport. J. Clïir., 2, 1173-1181.

Leaman, K.D., R.L. Molinari, and P.S. Vertes, 1987: Structure and variability of the Florida Current at $27^{\circ} \mathrm{N}$ April 1982-July 1984. J. Phys. Oceanogr., 17, $565-583$.

Leaman, K.D., E. Johns, and T. Rossby, 1989: The average distribution of volume transport and potential vorticity with temperature at three sections across the Gulf Stream. J. Phys. Oceanogr., 19, 565-583.

Levitus, S., 1982: Climatological atlas of the world ocean, Prof. Pap. 13, Natl. Oceanic and Atmos. Admin., 173 pp.

Malanotte-Rizzoli, P., 1994: Data assimilation: fundamentals, goals, and Mediteranean examples, in Ocean Processes in Climate Dynamics: Global and Mediterranean Examples, Malanotte-Rizzoli and Robinson, eds. Kluwer Academic, 323354.

Marotzke, J., 1992: The role of integration time in determining a steady state through data assimilation. J. Phys. Oceanogr., 22, 1556-1567.

Marotzke, J., 1994: Ocean models in climate problems, in Ocean Processes in Climate Dynamics: Global and Mediterranean Examples, Malanotte-Rizzoli and Robinson, eds. Kluwer Academic, 79-110.

Marotzke, J. and C. Wunsch, 1993: Finding the steady state of a general circulation model through data assimilation: application to the North Atlantic Ocean. $J$. Geophys. Res., 98, 20,149-20,167.

McWilliams, J.C., N.J. Norton, P.R. Gent, and D.B. Haidvogel, 1990: A linear balance model of wind-driven, midlatitude ocean circulation. J. Phys. Oceanogr., 20, 1349-1378.

Pedlosky, J., 1987: Geophysical Fluid Dynamics, $2^{\text {nd }}$ ed., Springer-Verlag, 710 pp.

Roemmich, D., 1981: Circulation of the Caribbean Sea: A well-resolved inverse problem. J. Geophys. Res., 86, 7993-8005.

Roemmich, D. and C. Wunsch, 1985: Two transatlantic sections: Meridional circulation and heat flux in the subtropical North Atlantic Ocean. Deep Sea Res., 32, 619-664. 
Schmitt, R.W., P.S. Bogden, and C.E. Dorman, 1989: Evaporation Minus Precipitation and Density Fluxes for the North Atlantic. J. Phys. Oceanogr., 19, $1208-1221$.

Stommel, H., 1948: The westward intensification of wind-driven ocean currents. Trans. Amer. Geophys. Union, 99, 202-206.

Stommel, H., 1958: The abyssal circulation. Deep Sea Res., 5, 80-82.

Stommel, H. and A.B. Aarons, 1959: On the abyssal circulation of the world ocean-II. An idealized model of the circulation pattern and amplitude in oceanic basins. Deep Sea Res., 6, 217-233.

Thacker, W.C., 1988: Fitting models to inadequate data by enforcing spatial and temporal smoothness. J. Geophys. Res., 93, 10,655-10,665.

Thacker, W.C. and R.B. Long, 1988: Fitting dynamics to data. J. Geophys. Res., 93, $1227-1240$.

Trenberth, K.E., and A. Solomon, 1993: The global heat balance: heat transports in the atmosphere and ocean. Clim. Dyn., (submitted).

Tziperman, E. and W.C. Thacker, 1989: An optimal-control/adjoint-equations approach to studying the oceanic general circulation. J. Phys. Oceanogr., 19, 1471-1485.

Tziperman, E., W.C. Thacker, R.B. Long, and S.-M. Hwang, 1992a: Oceanic data analysis using a general circulation model, I, simulations. J. Phys. Oceanogr., 22, 1434-1457.

Tziperman, E., W.C. Thacker, R.B. Long, S.-M. Hwang, and S.R. Rintoul, 1992b: Oceanic data analysis using a general circulation model, II, a North Atlantic model. J. Phys. Oceanogr., 22, 1458-1485.

Veronis, G. 1975: The role of models in tracer studies, in Numerical Models of the Ocean Circulation. National Academy of Sciences, 133-146.

Yu, L. 1993: private communication. 